\title{
Diferencias de género en la elección del sitio de trabajo en un contexto de crisis
}

\author{
Lilia Dominguez V. y Flor Brown G.
}

RESUMEN

Trabajar desde el domicilio es una opción que difiere de otras formas laborales. Detrás de esta modalidad de trabajo no solo están la globalización y la subcontratación, sino también las relaciones desiguales de género en el hogar. Mediante una estimación de dos regresiones multilogísticas, se demuestra que las características del trabajo domiciliario y fuera de este, como también del desempleo, difieren entre sexos tanto en la distribución de los rangos de edad entre hombres y mujeres por sitio de trabajo, como con respecto a nivel de escolaridad, estado civil y ubicación por niveles de urbanización, lo que sugiere que dichas características afectan en distinta forma a las decisiones de ambos sexos. Con relación al efecto de la crisis, los resultados sugieren que esta afectó agudamente al empleo de la población trabajadora desde el domicilio para el sector manufacturero, particularmente a la masculina, mientras que la ensanchó en el sector servicios.

PALABRAS CLAVE

CLASIFICACIÓN JEL

AUTORES
Mujeres, trabajo en casa, empleo de la mujer, productos manufacturados, sector terciario, datos estadísticos, México

$101,116, \mathrm{~J} 20, \mathrm{C} 35$

Lilia Domínguez V. es profesora e investigadora del Posgrado de la Facultad de Economía de la Universidad Nacional Autónoma de México (UnAM).1dv@unam.mx

Flor Brown G. es profesora e investigadora del Posgrado de la Facultad de Economía de la Universidad Nacional Autónoma de México (UNAM). brown@unam.mx 


\section{I}

\section{Introducción}

La economía informal constituye el 48,5\% del empleo total en América Latina (Tokman, 2008). En ella se ubican aquellos trabajadores carentes de los beneficios de la seguridad social, capacitación, protección de ingresos, atención médica y pensiones otorgados por las leyes laborales y que, por lo tanto, tienen un importante índice de vulnerabilidad. Es un segmento laboral dinámico y heterogéneo, que incluye a trabajadores independientes en actividades de subsistencia, trabajadores domésticos, trabajadores desde el domicilio, asalariados e independientes con pequeños emprendimientos y trabajadores sin prestaciones en empresas formales (OIT, 2005). No solo esta magnitud es preocupante, también lo es que - como resultado del proceso globalizadorcobraran relevancia nuevas formas de contratación y los gobiernos comenzaran a desregular los mercados de trabajo para propiciar mayor flexibilidad en el empleo y facilitar la subcontratación de pequeñas empresas informales o desde el domicilio. De tal forma que, si bien el sector informal creció apenas un 1,7\% entre 1990 y 2008, el empleo con salarios precarios en la región pasó de un 11\% al 15,1\% (Tokman, 2008).

La economía mexicana no es la excepción. Hay algunas diferencias en las estimaciones, pero todas coinciden en la elevada participación del empleo informal en la economía. Según Tokman (2008), el empleo del sector informal representaba el $43,7 \%$ del empleo total y el empleo de salarios precarios un $14,8 \%$ en 2008. A su vez, Cardero y Espinosa (2013) estiman en 64\% el trabajo informal para 2009, a partir de la carencia de acceso a los programas de bienestar y salud provenientes del empleo.

En el trasfondo de esta situación es necesario mencionar que las reformas estructurales de la política neoliberal, iniciadas con la crisis de la deuda externa en 1982, lograron un cambio en el motor de la economía y mayor estabilidad en algunos indicadores macroeconómicos, tales como la deuda pública externa, el déficit público y la inflación. Sin embargo, los

\footnotetext{
$\square$ Nuestro agradecimiento a los colegas Jenny Cooper y Julio López por su apoyo a lo largo del trabajo, y a los evaluadores anónimos por sus observaciones acuciosas, lo que permitió enriquecer el trabajo; asimismo, al Programa de Apoyo a Proyectos de Investigación e Innovación Tecnológica de la UNAM por los fondos proporcionados al proyecto IN306911-3.
}

indicadores de desempeño productivo y empleo no han llenado las expectativas que generaron (Ocampo y Ros, 2011). En efecto, por una parte el crecimiento económico ha alcanzado tasas relativamente moderadas si se comparan con las de los países emergentes asiáticos e incluso latinoamericanos. Entre 1988 y 1994 el producto interno bruto (PIB) creció un 3,4\%; de 1994 a 2000, los años de ingreso al Tratado de Libre Comercio de América del Norte (TLCAN) correspondientes con el auge estadounidense, el PIB aumentó un 3,6\%, y apenas alcanzó a un 2,2\% en el período 2001-2011.

Más grave aún, el nuevo esquema de crecimiento orientado a las exportaciones tampoco ha logrado satisfacer las necesidades de empleo de una población en expansión, en tanto que su incremento ha sido relativamente bajo en los últimos 25 años, con tasas medias de 2,7\% entre 1988 y 1993; 2,2\% de 1995 a 2000, y de $1,7 \%$ de 2001 a 2011. La tasa abierta de desempleo, aunque no permite apreciar la situación en materia de subutilización de la fuerza de trabajo, se amplía al pasar de un $2,2 \%$ a un $5,2 \%$ en el último subperíodo.

En este contexto de desequilibrio creciente entre el aumento de la oferta de fuerza de trabajo y la caída de su demanda, se acelera paradójicamente el ritmo con que las mujeres se incorporan a la producción y distribución de mercancías (De Oliveira y Eternod, 2000; Rendón y Salas, 2000; García, 2001). A partir de los años ochenta se acrecentó la tasa de participación femenina y se generalizó en todos los grupos de edad y distintos estados civiles. Si bien hay factores sociales, culturales y demográficos que explican lo anterior, el descenso de los salarios reales a partir de la crisis de 1982 reforzó la necesidad de las mujeres de salir al mercado de trabajo, en un entorno de inestabilidad económica y en condiciones muy desfavorables ante la ausencia de seguros de desempleo y prestaciones universales. Aunque las transformaciones del mercado laboral han afectado a ambos sexos, es innegable que las mujeres se concentran en algunas de las categorías más desprotegidas de la fuerza de trabajo (García, 2001) ${ }^{1}$.

\footnotetext{
1 El empleo informal de las mujeres se concentra y aumenta en el comercio (del $31 \%$ en 2000 al 34,3\% en 2009); en los servicios diversos (21,3\% en 2009) y en la industria (13,3\%) (Cardero y Espinosa, 2013).
} 
Dentro del trabajo informal se ubica aquel que se realiza en los hogares para el mercado y que existe desde el comienzo de la revolución industrial y va adquiriendo nuevas modalidades ante los cambios en la demanda de trabajo. Con las recurrentes crisis económicas, los trabajadores por cuenta propia registraron una elevada participación económica en el caso de las mujeres adultas e hijos varones (García, 2001). Según la Encuesta Nacional de Ocupación y Empleo (ENOE), hoy en día esta modalidad de trabajo tiene una cobertura cercana al $14 \%$ del total de la fuerza laboral en México: 4,4 millones de empleados en 2010, lo que significa casi la tercera parte del total de trabajadores informales. Por su parte, la segregación de género está presente en el empleo desde el domicilio. Las mujeres predominan en el trabajo desde la propia vivienda ${ }^{2}$ con el $10,2 \%$, comparado con un 2,6\% de los hombres. En la manufactura, el trabajo desde el hogar es frecuente en la industria del vestido, cuero y calzado, muebles y maquinaria; en tanto que en los servicios lo es en el comercio al menudeo de alimentos (abarrotes), papelería y ropa, así como en los servicios profesionales.

En cambio, el 12,8\% del total de los hombres empleados acuden a laborar en el domicilio del patrón, mientras que solo lo hacen un 3,9\% de las mujeres; tal es el caso de las trabajadoras domésticas, los choferes y los asalariados que trabajan para micronegocios en viviendas.

Esta segregación plantea una inquietud por entender cuáles son las modalidades características del trabajo desde el propio domicilio en comparación con otras opciones, como pueden ser emplearse en una oficina, fábrica o institución fuera del hogar o mantenerse al margen de la fuerza de trabajo. El objetivo de este estudio es examinar los factores que intervienen en la decisión de hombres y mujeres para elegir dónde y cómo trabajar $^{3}$ en comparación con la opción de permanecer

\footnotetext{
2 Más del $80 \%$ de esta modalidad se realiza por cuenta propia según la ENOE.

${ }^{3}$ Es importante subrayar que se debe estar consciente de que las mujeres (y algunos hombres) realizan trabajo no remunerado en su propio domicilio para la crianza de los hijos, el cuidado de los dependientes mayores y la atención del día a día del hogar de la familia. Sin duda este trabajo doméstico es tan valioso como el que se efectúa para el mercado. Sin embargo, para simplificar, en este estudio el trabajo desde el hogar o en el propio domicilio se refiere exclusivamente al trabajo extradoméstico que se realiza para el mercado y que genera un ingreso.
}

fuera de la fuerza de trabajo. En particular, las opciones que se examinarán son: el trabajo desde la propia vivienda en la manufactura o en los servicios, acudir a trabajar fuera del domicilio o no emplearse.

Otra preocupación es investigar cómo afectó la crisis de 2008 tanto al trabajo desde el domicilio como al desarrollado fuera de este. Como es sabido, entre los países de América Latina, México fue el más afectado por dicha crisis, pues entre 2008 y 2009 experimentó una caída del PIB total y del PIB manufacturero del 5,9\% y 9,9\%, respectivamente (Instituto Nacional de Estadística y Geografía (INEGI)), y un aumento del $20 \%$ en la tasa de desempleo, que pasó de un $4 \%$ a un 5,5\% en los mismos años, ello aunado al incremento del trabajo informal y de las condiciones precarias que lo acompañan, y es de esperar un cambio tanto en su magnitud como en sus determinantes.

De acuerdo con Edwards y Field-Hendrey (2002) y Rani y Unni (2009), en el presente estudio se utiliza un modelo multinomial para los años 2005 y 2010 , que permite analizar en forma simultánea las decisiones de trabajar desde el propio domicilio en manufactura o servicios o fuera del hogar, en comparación con permanecer fuera de la fuerza de trabajo. La fuente de información utilizada es la ENOE respecto de los mismos años. Para el caso de México es escasa la literatura acerca del trabajo desde el hogar. Un interesante estudio a partir de una encuesta ad hoc para analizar las condiciones de trabajo desde el domicilio en el sector manufacturero, su naturaleza y las relaciones laborales es el de Benería y Roldán (1992), por lo que constituye un reto para las autoras de esta investigación analizar en forma econométrica los factores subyacentes a esta modalidad laboral en la manufactura y los servicios.

Como se expone en la sección II, la explicación de por qué existe trabajo desde el hogar es compleja y requiere considerar múltiples factores. En la sección III se presentan las diferencias entre las distintas modalidades de trabajo: desde el hogar, ya sea en la manufactura o los servicios; fuera del domicilio y fuera de la fuerza de trabajo. Para analizar la probabilidad de que hombres o mujeres opten por cualquiera de estas modalidades, se estima un modelo multinomial cuya metodología y resultados se encuentran en la sección IV; en tanto que en la sección V se entregan las consideraciones finales. 


\section{II}

\section{Aspectos fundamentales acerca del trabajo desde el domicilio}

En algunos análisis desde la perspectiva marxista se sugiere que el trabajo desde el domicilio se ha profundizado a raíz de las necesidades del sistema capitalista globalizado, que requiere trabajo flexible y útil para subcontratar en condiciones de costos menores, pasando por alto la legislación laboral y por tanto sin prestaciones (Pearson, 2004). Así, el aumento del trabajo desde el domicilio es el resultado de la informalidad, que es el factor clave para entender las relaciones entre la producción globalizada y el trabajo desde la vivienda (Benería, 1981; Carr, Chen y Tate, 2000).

Sin duda, la apertura comercial ha generado presiones a la baja de los costos de producción, lo que propicia la subcontratación en el sector informal en condiciones desventajosas (Pearson 2004; Benería y otros, 2000). En México, como en otros países del tercer mundo insertos en las cadenas globales de valor de la industria textil y del vestido (Dedeoglu, 2010), la presencia de maquiladoras intensificó el uso del trabajo desde los domicilios por parte de empresas de la industria del vestido que subcontratan la ejecución de operaciones específicas (pegado de botones, dobladillos, cosido de encaje y bordados) (López, 2005; Juárez, 2004). Sin embargo, habría que tener cuidado de no exagerar la relevancia de la subcontratación internacional como causa principal del trabajo desde el hogar, porque es sabido que en general las exportaciones se basan en un altísimo contenido de importaciones de insumos en perjuicio de los proveedores locales, lo que reduce la demanda de bienes y servicios y debilita los lazos intra e intersectoriales que formaban las cadenas productivas internas (Aroche y Cardero, 2007). La subcontratación, en consecuencia, tiene lugar en nichos específicos, por ejemplo, en la industria del vestido donde por cada hombre contratado hay 2,65 mujeres según datos del INEGI.

Un factor adicional en la aparición de nuevas modalidades de trabajo desde el domicilio que se aprecian en el caso mexicano - sobre todo respecto de los hombres con altos niveles de formación educativa que trabajan en los servicios- debe buscarse en las nuevas formas de organización de la producción derivadas de la especialización flexible (Piore y Sabel, 1984) y de los cambios técnicos que han posibilitado la fragmentación del proceso productivo, la descentralización de la producción y la desintegración vertical de las empresas (Gereffi, Humphrey y Sturgeon, 2005; Langlois, 1995) que deciden comprar en el mercado algunos servicios que antes se producían internamente. Por último, también habría que mencionar que la lucha de las empresas por flexibilizar las condiciones laborales y lograr ahorros en tiempo y espacio, conjugada con la creciente utilización de tecnologías de la información en las distintas labores de la firma que facilitan el monitoreo, está propiciando el trabajo desde el domicilio de algunos de sus trabajadores. La idea del "trabajo virtual" (es decir, de trabajadores que realizan sus tareas fuera de la oficina) ha estado presente desde hace un tiempo, pero hasta hace poco era sinónimo de trabajar desde el hogar o de "teletrabajo". No se trata de comprar el servicio afuera, sino de trasladar la oficina a la casa. Los avances en la tecnología móvil facilitan cada vez más las reuniones virtuales, evitando los costos de los viajes y la pérdida de tiempo laboral (Cerda, 2011).

En este trabajo se quiere enfatizar el juicio de Atasü Topçuoglu (2005), para quien las relaciones entre la globalización económica, la informalización y el trabajo desde el domicilio son importantes, pero no suficientes para entender el fenómeno, pues finalmente este tipo de trabajo data desde antes de la Revolución Industrial (Thompson, 1963; Louw y De Vries, 2002). También hay que considerar las relaciones de género de carácter patriarcal, que inciden en la limitación que enfrentan las mujeres para trabajar en el mercado en situación de igualdad con los hombres y hacen invisible el carácter informal del trabajo desde el domicilio, que no es siempre una opción atractiva, sino una necesidad. Como señala Hartmann (1979), la posición de las mujeres en el mercado de trabajo es dual: son dependientes de los salarios de sus esposos, por ello deben realizar el trabajo doméstico. A la vez, sus responsabilidades hogareñas debilitan su posición en el mercado, lo que redunda en menores salarios en comparación con los de los hombres. En otras palabras, el trabajo desde el domicilio es una oportunidad para que las mujeres trabajen y ganen un ingreso sin cuestionar la ideología patriarcal (Kantor, 2003). 
Como consecuencia, el mercado laboral no es neutro en cuestiones de género. Debe reconocerse que hay normas informales y culturales que determinan la segregación de género en ciertos sectores de la economía y en modalidades de trabajo, así como la segregación vertical (Elson, 1999). Igualmente, las construcciones socioculturales de los roles y estereotipos de género establecen quién es la autoridad en la toma de decisiones o la propiedad de los activos económicos (Benería y Roldán, 1987).

Visto así, existe una gama de variables a considerar en la explicación de por qué hay un segmento de la población que se gana la vida con un empleo desde su domicilio. En trabajos recientes se incorporan las características sociodemográficas de los trabajadores, como su nivel educativo, edad, religión, aspectos raciales y los costos laborales que conlleva el trabajo fuera del hogar, aspectos que son importantes en el caso de las mujeres que, a diferencia de los hombres, tienen que realizar las actividades del hogar conjuntamente con las del mercado. Esto puede motivar que su salario de reserva sea más bajo que si laborara fuera del hogar. Un estudio pionero es el de Edwards y Field-Hendrey (2002), quienes utilizaron los datos oficiales del Censo de Población de 1990 de los Estados Unidos de América. En este trabajo, se parte del concepto del costo fijo de participar en el mercado laboral a fin de examinar las decisiones que toman las mujeres para trabajar en el hogar, y encuentran que aquellas con hijos, dependientes o que viven en áreas rurales tienen mayores probabilidades de trabajar desde el domicilio que fuera de este. A la vez, se muestra que las mujeres con hijos, cónyuge o dependientes tienen mayor potencial para realizar conjuntamente tanto el trabajo doméstico no remunerado como el que se efectúa para el mercado desde su hogar. Las autoras enfatizan el atractivo que tiene para las mujeres permanecer en su casa con el fin de combinar el trabajo doméstico y el del mercado, obteniendo un ingreso por este último.

Por su parte, Rani y Unni (2009) analizan el caso de la India con un modelo similar, pero tomando también en consideración el contexto económico con el fin de examinar la posible importancia de la subcontratación derivada de las reformas económicas. Centran su interés en los determinantes de la decisión de hombres y mujeres de trabajar desde el hogar en la manufactura o los servicios, o de hacerlo fuera del domicilio. Con respecto a las mujeres, las autoras encuentran que la decisión de trabajar desde el hogar está determinada, en una perspectiva micro, por el medio cultural (castas, religión), la escolaridad y el costo fijo de laborar en casa, aspectos que no están presentes en las decisiones de los hombres, ya que no fueron significativos. En otras palabras, comprueban la importancia para las mujeres de los sistemas patriarcales.

Ahora, desde un punto de vista macro, Rani y Unni (2009) comparan épocas de menor apertura comercial con años más recientes y hallan que no existe una relación significativa del trabajo desde el domicilio con las mujeres, pero sí con los hombres. Lo anterior sugiere que la baja, pero creciente participación masculina en el trabajo desde el domicilio se explica por las reformas económicas que han afectado a la organización de la producción entre los hombres. Es decir, que si bien las condicionantes socioculturales son evidentes en la decisión de las mujeres de emprender trabajo desde el domicilio, para los hombres no lo son y pueden satisfacer trabajos de subcontratación acordes con las exigencias económicas industriales de reducción del costo laboral en un mercado crecientemente globalizado.

Tomando como antecedentes estos dos últimos estudios, se intenta aquí una explicación del trabajo desde el domicilio y fuera de este mediante un enfoque de género en un nivel tanto micro como macro, cuyos detalles se ofrecen más adelante en la sección IV. 


\section{III}

\section{Hechos estilizados en el trabajo manufacturero y de servicios desde el domicilio y fuera de este, 2005-2010}

A pesar de la creciente inserción de las mujeres en el mercado laboral a finales del siglo XX, su participación en el total de la fuerza de trabajo sigue siendo relativamente baja; solo un 38\% de ellas están empleadas, en tanto que el 86\% de los hombres lo están en 2005. Sin embargo, se aprecia que en los cinco años en estudio el empleo femenino se amplió más rápido que el de los hombres, y en 2010 el $42 \%$ de las mujeres estaban empleadas y también el $84 \%$ de los hombres, lo que sugiere una mayor repercusión de la crisis con respecto a ellos. Se advierte una ligera caída en el número de mujeres que trabajan desde su hogar en la manufactura y los servicios, ya que de representar un $15 \%$ en 2005 pasaron a un $12 \%$ en 2010 (véase el cuadro 1). Si bien la cifra de los hombres empleados desde el domicilio se mantuvo en un 3\%, se constata un cambio en la composición: mientras que en 2005 un 5\% de ellos trabajaban desde su hogar en la manufactura y un $1 \%$ en los servicios, en 2010 los porcentajes fueron de un $1 \%$ y un $2 \%$, respectivamente. Es decir, hubo una caída de un 3,7\% anual en el caso de aquellos que lo hacen para el sector manufacturero y un incremento en el de los que emprendieron un negocio domiciliario por su cuenta en los servicios, donde la participación femenina a pesar de descender siete puntos porcentuales, sigue siendo muy elevada: más del doble del promedio (véase el cuadro 1).

En el trabajo fuera del domicilio, concepto que se refiere a ocuparse en una fábrica, oficina o trabajo informal en la calle o en el domicilio del patrón, en el cuadro 1 se observa que el $97 \%$ de los hombres, comparado con el $85 \%$ de las mujeres, trabajaban en esta modalidad en 2005 , y el $97 \%$ y el $88 \%$, respectivamente, en 2010 . Es decir, hubo un ligero aumento de mujeres trabajando fuera de su domicilio en este período, lo que no se esperaría en el contexto de la crisis. Una posible explicación es que estas dejaran de trabajar por cuenta propia para hacerlo en el domicilio del patrón, en el comercio ambulante dentro del sector informal o en oficinas y fábricas en el sector formal. Su presencia pasa del 32\% al 34\% del total de la fuerza de trabajo empleada (por debajo de su participación promedio en el total de la economía) en el período de estudio.
Del total de mujeres fuera de la fuerza de trabajo, más del $80 \%$ se consideran "no disponibles", es decir, estudian o están jubiladas, pero sobre todo están casadas y se quedan en el domicilio para el cuidado de los hijos y la atención del hogar, cuestión que es mucho menos importante en el caso de los hombres, como resalta en las estadísticas que se presentan en el cuadro 1.

En los cinco años del período se observa (véase el cuadro 1) que el número de desempleados se amplió en una magnitud considerable (12\%), con mayor énfasis en las mujeres cuya tasa fue de un $14 \%$ en comparación con un $11 \%$ en el caso de los hombres ${ }^{4}$. Dentro de esta categoría, el incremento de la población femenina disponible fue de un $5 \%$, en tanto que bajó la tasa de las no disponibles. En los hombres sucedió lo contrario, porque los no disponibles aumentaron un 3\% promedio anual.

Debido a que el interés del presente estudio se focaliza en el análisis del trabajo desde el propio domicilio u hogar (home based workers), se identifica una submuestra ${ }^{5}$ de la ENOE para los años $2005^{6}$ y 2010 , correspondiente a jefes y jefas o esposos y esposas de cada domicilio. No se consideraron las observaciones que atañen a las hijas, hijos u otros miembros del hogar en edad de trabajar, bajo el supuesto de que ellos no tendrían la capacidad de emprender un negocio en un domicilio que no es el propio. Se concede que pueda haber excepciones en que los hijos pongan un negocio en el hogar de los padres, pero se consideran menos importantes.

La ENOE registra 105.342 hogares a partir de los cuales se hacen los cálculos para toda la población con

\footnotetext{
4 La tasa de desempleo es de 2,2\% en 2005 y de 3,5\% en 2010 , ligeramente superior entre las mujeres, con $2,3 \%$ en el primer año y $3,7 \%$ en el último, en comparación con $2,2 \%$ y $3,4 \%$, respectivamente, de los hombres. Esta tasa de desempleo es menor que la tasa promedio de la economía, porque en México la tasa de desempleo juvenil entre la población de referencia (de 15 a 24 años de edad) históricamente ha sido poco más del doble que en las personas de más de 25 años y la submuestra se concentra en los rangos superiores a esa edad.

5 Es una submuestra porque la ENOE tiene información de todos los miembros del hogar. Sin embargo, de aquí en adelante en este trabajo se hará referencia a ella como "la muestra".

${ }^{6}$ El primer año de esta encuesta fue 2005.
} 


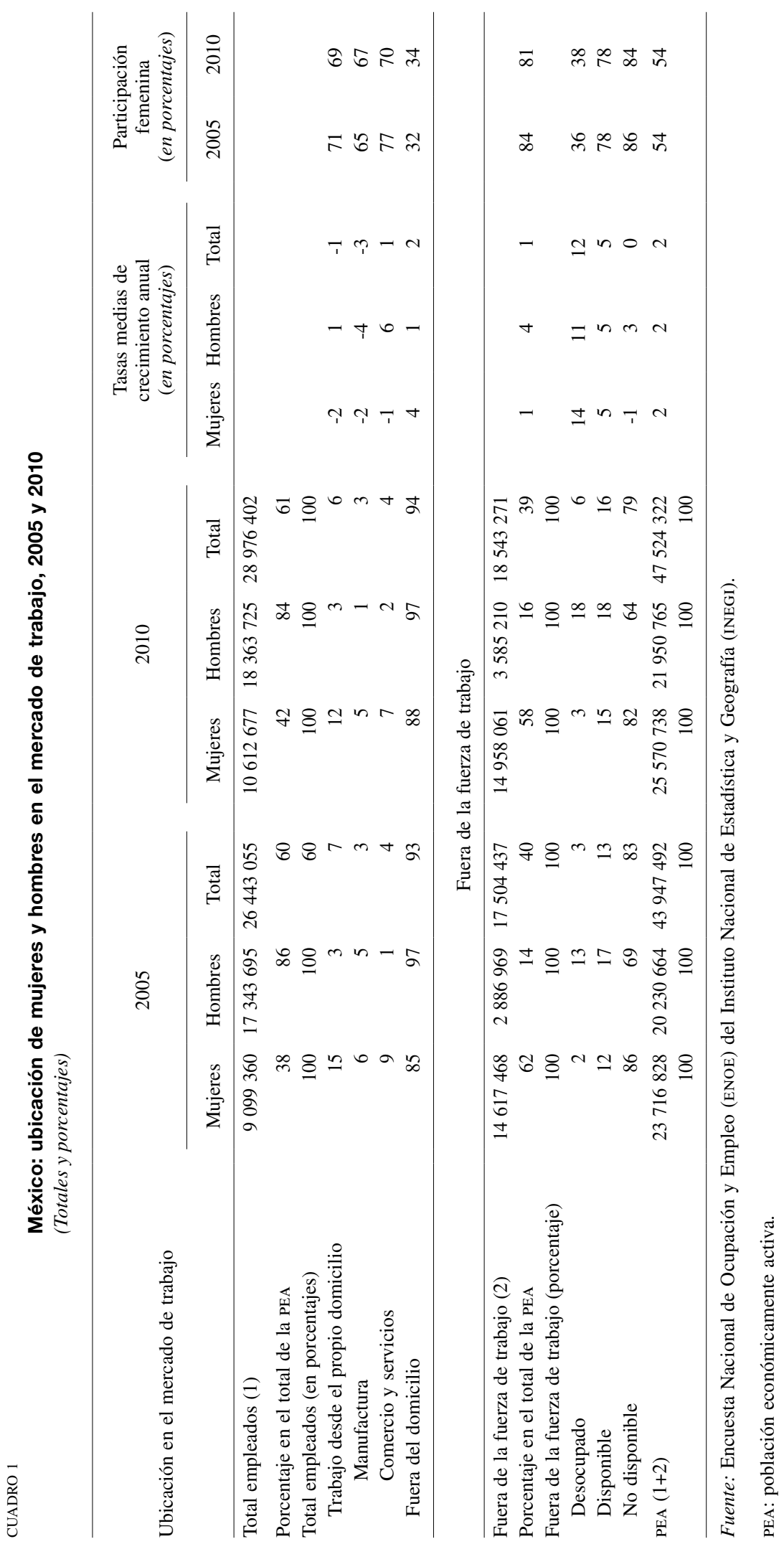


un factor de expansión. El número de observaciones de la muestra utilizada fue de 81.223 jefes de hogar o esposos y 95.834 jefas o esposas. En el cuadro 2 se presentan las características de la composición de los hogares de la muestra. Como era de esperarse, los hombres son los jefes de hogar en un alto porcentaje (96\%), en tanto que en el caso de las mujeres solo un $25 \%$ de ellas son jefas de hogar. Si se considera que los dependientes que pueden requerir cuidado están constituidos por los hijos menores de 12 años y los adultos mayores que no trabajan ${ }^{7}$ y viven en el hogar, se observa que un alto porcentaje de los hogares los tienen (55\% en la muestra de los hombres y $43 \%$ en la de las mujeres). Como es sabido, de estos dependientes los hijos son los más importantes.

CUADRO 2

\section{México: composición del hogar en la muestra}

(En porcentajes)

\begin{tabular}{lcc}
\hline & \multicolumn{2}{c}{ Promedio 2005-2010 } \\
\cline { 2 - 3 } & Hombres & Mujeres \\
\hline Jefe/a de hogar & 96 & 25 \\
Esposo/a & 4 & 75 \\
Hijos hasta 7 años de edad & 22 & 19 \\
Hijos de 8 a 12 años de edad & 24 & 20 \\
Dependientes mayores & 8 & 3 \\
Total & 55 & 43 \\
\hline
\end{tabular}

Fuente: Encuesta Nacional de Ocupación y Empleo (ENOE) de 2005 y 2010 del Instituto Nacional de Estadística y Geografía (INEGI).

Se aprecia que los atributos de los trabajadores son distintos entre hombres y mujeres (véanse los cuadros 3 y 4). Los hombres que están fuera de la fuerza de trabajo tienden a ser mayores de 45 años (80\%), lo que puede interpretarse como la dificultad para encontrar un empleo en tales circunstancias. Por su parte, la edad de las mujeres fuera de la fuerza de trabajo se distribuye más o menos equitativamente entre los distintos estratos de edad, lo que también refleja la decisión de no trabajar para cuidar a los hijos, como ha sido corroborado en distintos estudios (Maldonado y Rendón, 2004). El estrato con mayor participación en hombres y mujeres es el de 35 años a 44 años en el trabajo desde el domicilio. Pero se observa que en comparación con ellas, los hombres tienden a trabajar hasta edades superiores a los 60 años. Por último, la mujer que trabaja fuera de su domicilio

\footnotetext{
7 Estos fueron definidos como mayores de 65 años, sin trabajo.
}

tiende a ser más joven que ellos (ya que la mayoría tiene menos de 45 años), incluso en comparación con aquellas que trabajan en su hogar.

Un cambio que se advierte en estos cinco años es que la población que emprende un negocio en su vivienda tiende a ser de mayor edad. Esto ocurre en particular entre las mujeres, en las que el trabajo desde el domicilio en la manufactura o los servicios constituía en promedio el $35 \%$ del total en los rangos mayores de 45 años en 2005, proporción que sube casi al 50\% en 2010 , mientras que en los hombres dicha proporción pasa del $50 \%$ al $58 \%$. Cabe reflexionar sobre si esto obedece a la falta de oportunidades de empleo debido a la crisis.

En términos generales, una mayor escolaridad se relaciona con un ingreso más elevado y mejores condiciones en el empleo y, en el caso de la mujer, la escolaridad ha probado ser de gran importancia para explicar su participación en el mercado de trabajo (Maldonado y Rendón, 2004). Si se consideran niveles de secundaria o inferiores como punto de referencia, tal como se esperaría, la escolaridad tiende a ser baja tanto en hombres como en mujeres fuera de la fuerza de trabajo: alrededor de un 25\% tienen estudios de primaria. En el caso del trabajo en el hogar, el 77\% de las mujeres en promedio tienen un nivel menor de preparatoria. En cambio, un mayor porcentaje de hombres que de mujeres con más años de escolaridad realizan trabajo desde el domicilio en la manufactura en 2005 y especialmente en los servicios, donde sucede algo interesante: la participación de jefes de hogar con preparatoria y profesional aumenta del $35 \%$ al $44 \%$. Ello podría derivar del proceso de descentralización de la producción y desintegración vertical de las empresas que se mencionó con anterioridad. Puede también ser una respuesta de autoempleo de personas con mayor educación ante la crisis. Finalmente, se corrobora que la escolaridad puede implicar mayores deseos de superación personal y de búsqueda de independencia económica (García y Pacheco, 2000). Así, las jefas de hogar sobresalen por su nivel de escolaridad más alto en el trabajo fuera del hogar en comparación con el trabajo desde la vivienda, así como también en parangón con los hombres.

En los cuadros 3 y 4 se constata que el estado civil predominante es la unión matrimonial seguida de unión libre, es decir, la relación de pareja; con la excepción de los desempleados, se aprecia que —independientemente de la posición de empleo- los porcentajes son superiores en el caso de los hombres, o sea, hay un porcentaje más alto de mujeres solas y, 
CUADRO 3

México: características de las trabajadoras, 2005 y 2010

(En porcentajes con respecto al total)

\begin{tabular}{|c|c|c|c|c|c|c|c|c|}
\hline \multirow{2}{*}{ Mujeres } & \multicolumn{2}{|c|}{$\begin{array}{l}\text { Fuera de la fuerza } \\
\text { de trabajo }\end{array}$} & \multicolumn{2}{|c|}{$\begin{array}{l}\text { Desde domicilio } \\
\text { en manufactura }\end{array}$} & \multicolumn{2}{|c|}{$\begin{array}{l}\text { Desde domicilio } \\
\text { en servicios }\end{array}$} & \multicolumn{2}{|c|}{ Fuera del domicilio } \\
\hline & 2005 & 2010 & 2005 & 2010 & 2005 & 2010 & 2005 & 2010 \\
\hline \multicolumn{9}{|l|}{ Por rangos de edad } \\
\hline 15-25 años & 10 & 9 & 8 & 4 & 6 & 4 & 5 & 6 \\
\hline 25-35 años & 22 & 19 & 29 & 20 & 25 & 18 & 25 & 23 \\
\hline 35-45 años & 22 & 20 & 33 & 28 & 31 & 27 & 37 & 33 \\
\hline 45-60 años & 26 & 27 & 23 & 33 & 29 & 35 & 28 & 31 \\
\hline más de 60 años & 20 & 25 & 7 & 15 & 9 & 16 & 5 & 7 \\
\hline Total & 100 & 100 & 100 & 100 & 100 & 100 & 100 & 100 \\
\hline \multicolumn{9}{|l|}{ Por niveles de escolaridad } \\
\hline Menos que primaria & 12 & 11 & 10 & 15 & 8 & 9 & 6 & 5 \\
\hline Primaria & 46 & 41 & 42 & 47 & 40 & 43 & 25 & 26 \\
\hline Secundaria & 20 & 23 & 27 & 22 & 23 & 24 & 15 & 23 \\
\hline Preparatoria o escuela técnica & 7 & 9 & 7 & 7 & 9 & 9 & 10 & 13 \\
\hline Profesional & 15 & 16 & 14 & 9 & 20 & 15 & 44 & 33 \\
\hline Total & 100 & 100 & 100 & 100 & 100 & 100 & 100 & 100 \\
\hline \multicolumn{9}{|l|}{ Por estado civil } \\
\hline Soltero & 3 & 4 & 7 & 5 & 10 & 6 & 3 & 11 \\
\hline Casado & 71 & 67 & 64 & 64 & 60 & 61 & 71 & 58 \\
\hline Unión libre & 13 & 15 & 11 & 13 & 11 & 13 & 13 & 14 \\
\hline Separado & 3 & 3 & 7 & 6 & 8 & 7 & 3 & 7 \\
\hline Viudo & 9 & 10 & 8 & 10 & 6 & 10 & 9 & 6 \\
\hline Divorciado & 1 & 1 & 3 & 2 & 5 & 3 & 1 & 4 \\
\hline Total & 100 & 100 & 100 & 100 & 100 & 100 & 100 & 100 \\
\hline \multicolumn{9}{|l|}{ Por tamaño de la localidad } \\
\hline Más de 100000 habitantes & 57 & 55 & 63 & 36 & 68 & 57 & 57 & 65 \\
\hline Entre 15000 y 99000 habitantes & 12 & 12 & 14 & 13 & 12 & 13 & 12 & 13 \\
\hline Entre 2500 y 14999 habitantes & 12 & 12 & 12 & 21 & 10 & 13 & 12 & 11 \\
\hline Menos de 2500 habitantes & 19 & 21 & 11 & 30 & 10 & 17 & 19 & 11 \\
\hline Total & 100 & 100 & 100 & 100 & 100 & 100 & 100 & 100 \\
\hline
\end{tabular}

Fuente: Encuesta Nacional de Ocupación y Empleo (ENOE) 2005 y 2010 del Instituto Nacional de Estadística y Geografía (INEGI).

en particular en el caso de las separadas o divorciadas, estas tienden a trabajar ya sea en el hogar o fuera de este $^{8}$. Estar casado remite directamente a la presencia de responsabilidades familiares, por lo que se esperaría que una menor proporción de mujeres casadas estén empleadas (García y De Oliveira, 1994). De este modo, en tanto que el $84 \%$ y el $82 \%$ de las desempleadas están casadas o en unión libre en 2005 y 2010, respectivamente, este

8 Se observa que mientras un $13 \%$ de las mujeres solas están desempleadas y un $14 \%$ lo están en 2010, hay una mayor participación de mujeres solas trabajando en todas las modalidades de trabajo analizadas (en promedio: un $16 \%$ en 2005 y un $18 \%$ en 2010). porcentaje en las que están empleadas es en promedio del $76 \%$ y $74 \%$, respectivamente, en los mismos años, lo que no sucede en el caso de los hombres. A lo largo del período de estudio, se incrementa la proporción de mujeres casadas que trabajan en el hogar, y ocurre lo contrario entre las que trabajan fuera de él o se hallan desempleadas.

Por último, es importante el análisis de la distribución de la población en localidades rurales y urbanas, debido a los beneficios o desventajas que tienen los individuos al pertenecer a una localidad con diferente nivel de acceso a servicios, distintas culturas y tradiciones, y diversidad de oportunidades de empleo. 
CUADRO 4

México: características de los trabajadores, 2005 y 2010

(En porcentajes con respecto al total)

\begin{tabular}{|c|c|c|c|c|c|c|c|c|}
\hline \multirow{2}{*}{ Hombres } & \multicolumn{2}{|c|}{$\begin{array}{c}\text { Fuera de la fuerza } \\
\text { de trabajo }\end{array}$} & \multicolumn{2}{|c|}{$\begin{array}{l}\text { Desde domicilio } \\
\text { en manufactura }\end{array}$} & \multicolumn{2}{|c|}{$\begin{array}{l}\text { Desde domicilio } \\
\text { en servicios }\end{array}$} & \multicolumn{2}{|c|}{ Fuera del domicilio } \\
\hline & 2005 & 2010 & 2005 & 2010 & 2005 & 2010 & 2005 & 2010 \\
\hline \multicolumn{9}{|l|}{ Por rangos de edad } \\
\hline $15-25$ años & 4 & 4 & 4 & 2 & 3 & 2 & 3 & 6 \\
\hline 25-35 años & 6 & 6 & 20 & 15 & 18 & 13 & 18 & 22 \\
\hline 35-45 años & 9 & 10 & 26 & 28 & 25 & 25 & 25 & 29 \\
\hline 45-60 años & 21 & 23 & 32 & 35 & 35 & 38 & 35 & 32 \\
\hline más de 60 años & 60 & 57 & 18 & 20 & 19 & 22 & 19 & 11 \\
\hline Total & 100 & 100 & 100 & 100 & 100 & 100 & 100 & 100 \\
\hline \multicolumn{9}{|l|}{ Por niveles de escolaridad } \\
\hline Menos que primaria & 17 & 13 & 5 & 7 & 7 & 5 & 17 & 5 \\
\hline Primaria & 48 & 44 & 30 & 46 & 37 & 30 & 48 & 32 \\
\hline Secundaria & 12 & 15 & 22 & 28 & 21 & 21 & 12 & 26 \\
\hline Preparatoria o escuela técnica & 6 & 8 & 14 & 11 & 12 & 12 & 6 & 14 \\
\hline Profesional & 17 & 20 & 29 & 8 & 23 & 32 & 17 & 23 \\
\hline Total & 100 & 100 & 100 & 100 & 100 & 100 & 100 & 100 \\
\hline \multicolumn{9}{|l|}{ Por estado civil } \\
\hline Soltero & 7 & 9 & 4 & 4 & 6 & 7 & 4 & 5 \\
\hline Casado & 72 & 70 & 81 & 73 & 75 & 68 & 76 & 72 \\
\hline Unión libre & 8 & 10 & 12 & 16 & 14 & 16 & 15 & 18 \\
\hline Separado & 3 & 2 & 1 & 3 & 2 & 4 & 2 & 2 \\
\hline Viudo & 9 & 8 & 1 & 2 & 2 & 3 & 2 & 2 \\
\hline Divorciado & 1 & 1 & 1 & 2 & 1 & 2 & 1 & 1 \\
\hline Total & 100 & 100 & 100 & 100 & 100 & 101 & 100 & 100 \\
\hline \multicolumn{9}{|l|}{ Por tamaño de la localidad } \\
\hline Más de 100000 habitantes & 64 & 61 & 70 & 51 & 55 & 66 & 62 & 57 \\
\hline Entre 15000 y 99000 habitantes & 15 & 11 & 14 & 16 & 12 & 13 & 12 & 12 \\
\hline Entre 2500 y 14999 habitantes & 11 & 12 & 10 & 16 & 12 & 10 & 11 & 12 \\
\hline Menos de 2500 habitantes & 10 & 16 & 7 & 17 & 21 & 11 & 15 & 19 \\
\hline Total & 100 & 100 & 100 & 100 & 100 & 100 & 100 & 100 \\
\hline
\end{tabular}

Fuente: Encuesta Nacional de Ocupación y Empleo (ENOE) de 2005 y 2010 del Instituto Nacional de Estadística y Geografía (INEGI).

Los hombres tienden a estar más presentes en las zonas de mayor urbanización. Buena parte del trabajo en el hogar se realiza en las grandes ciudades, sobre todo en lo que se refiere a los servicios, donde trabajan desde el domicilio dos terceras partes del total de jefes y jefas de hogar. A lo largo del período, esta característica tendió a acentuarse en los servicios. Esto no sucede en la manufactura, donde las jefas de hogar que trabajaban en el domicilio en grandes ciudades alcanzaban al $62 \%$, pero en 2010 representaban solo un 36\%. Algo similar sucede con los jefes de hogar. En otras palabras, el trabajo desde el domicilio en la manufactura se volvió menos urbano. 


\section{IV}

\section{La decisión de trabajar desde el domicilio: un modelo multinomial}

\section{Aspectos metodológicos}

El modelo multinomial logit que se estimó parte de la idea central de que no existe un orden jerárquico entre las cuatro alternativas: trabajar desde el domicilio en la manufactura o los servicios, fuera de este o estar al margen del mercado laboral. El objetivo del modelo es calcular la probabilidad de que los individuos se ubiquen en cualquiera de estas alternativas. Las variables explicativas son factores exógenos que afectan a la oferta de trabajo en todas las condiciones mencionadas: salario de reserva, costos fijos de laborar fuera del hogar y condiciones macroeconómicas.

Como aproximaciones a la primera variable se incluyen la edad, la escolaridad y el grado de urbanización de la localidad donde vive el trabajador, que expresa el costo de desplazamiento. Como señalan los analistas, la edad denota experiencias personales y laborales que enriquecen el perfil ocupacional de los individuos; sin embargo, también es un factor que al incrementarse alude a deterioros físicos e intelectuales y, por tanto, aminora las posibilidades de que los adultos mayores sigan económicamente activos (Millán, 2010). De acuerdo con lo anterior, se esperaría de la edad un comportamiento no lineal, porque si bien conforme esta aumenta es mayor el salario de reserva, se llega a un punto en que la relación se revierte.

Asimismo, a mayor escolaridad se esperaría una probabilidad más elevada de trabajo fuera del hogar y que el trabajo desde el domicilio estuviera vinculado a menores niveles de escolaridad que el trabajo fuera de este.

Las personas residentes en áreas menos urbanizadas tienen más bajo salario de reserva a domicilio que fuera de este, en comparación con aquellas que residen en áreas urbanas. Sin embargo, las oportunidades laborales en las zonas rurales son escasas y trabajar desde el hogar en los servicios en estas zonas es poco frecuente y sería más probable que ocurriera en la manufactura. Debido a que hay costos de desplazamientos, se esperaría que a mayor urbanización aumente la probabilidad de trabajar desde el hogar en los servicios y fuera de este (Rani y Unni, 2009).

Los costos fijos están representados por las variables relacionadas con las responsabilidades del trabajo reproductivo y de cuidado, es decir, los hijos y dependientes económicos. Se esperaría que la presencia de estos, al elevar los costos fijos, aumente la probabilidad de trabajo desde el domicilio, en comparación con no participar, y disminuya el trabajo fuera del hogar. El tener una pareja puede implicar un incremento en las tareas del hogar y por tanto ser un obstáculo para emprender algún trabajo, pero sobre todo fuera de casa. Dado que ha sido tradicional que las responsabilidades del cuidado del hogar recaigan en las mujeres, no se espera una ligazón de estas variables con las decisiones laborales del sexo masculino. Acerca de la presencia de dependientes mayores, existen investigaciones en que se sugiere que estos pueden ayudar en el cuidado de los hijos (Knaul y Parker, 1997), pero también podría pensarse que con un estado de salud deficiente puedan implicar costos fijos mayores por necesitar cuidados que inhiben el empleo. En otros estudios no se ha encontrado evidencia al respecto (García y Pacheco, 2000).

Otros aspectos que podrían afectar a la participación de la mujer en el mercado laboral son las fluctuaciones en el empleo y el ciclo económico (Bover y Arellano, 1995).

En el presente estudio las condiciones macroeconómicas están representadas por el crecimiento del PIB en las entidades federativas, ponderadas por la participación en el empleo ${ }^{9}$. En el nivel macroeconómico, si el trabajo en la vivienda fuera un refugio para el desempleo, se esperaría que floreciera en entidades federativas de bajo o medio crecimiento. Por el contrario, si dicho trabajo es un complemento de modalidades laborales formales que subcontratan trabajo informal o compran bienes y servicios fuera de la empresa, se esperaría que se diera en entidades de alto o medio crecimiento. No hay hipótesis a priori para diferencias entre hombres y mujeres.

Por último, en opinión de las autoras del presente estudio, las dificultades financieras provocadas por la crisis podrían haber modificado la incidencia de algunas variables en la probabilidad de trabajar desde el domicilio. Por ejemplo, ante la presencia de hijos menores, Anderson

\footnotetext{
9 No hay estadísticas confiables sobre el trabajo en el hogar antes de 2005 que permitan realizar el mismo ejercicio.
} 
y Levine (1999) plantean que un incremento en el costo de cuidado disminuirá la probabilidad de participar en el mercado de trabajo. De modo que podría esperarse que - en el caso de las mujeres - un posible efecto de la crisis aumente la probabilidad de trabajo desde el domicilio y disminuya el trabajo fuera del hogar. Sin embargo, cabe la posibilidad de que la pérdida de ingresos familiares sea tal en los años de crisis que la presencia de hijos pequeños pierda importancia para restringir la inserción laboral de las mujeres adultas (García y De Oliveira, 1994).

La variable dependiente del modelo tiene distintos valores: "1" para el trabajo desde el domicilio en la manufactura; "2" para el mismo trabajo en los servicios; "3" para el trabajo fuera del domicilio, y "4" para fuera del mercado laboral. La descripción de las variables que se utilizaron para cada grupo se muestra en el cuadro 5 .

CUADRO 5

\section{Descripción de las variables independientes del modelo multilogístico}

\begin{tabular}{|c|c|c|}
\hline Salario de reserva & Costos fijos de trabajar fuera de casa & Condiciones macroeconómicas \\
\hline Edad & Hijos hasta 7 años $=1$ & $\begin{array}{l}\text { Estados federativos de bajo crecimiento: cuando } \\
\text { la tasa de crecimiento del PIB es menor que } 4,14 \\
\text { se asigna el número } 1\end{array}$ \\
\hline $\mathrm{Edad}^{2}$ & Hijos 8 a 12 años $=1$ & $\begin{array}{l}\text { Estados federativos de medio crecimiento: } \\
\text { cuando la tasa de crecimiento del PIB es mayor } \\
\text { o igual a } 4,15 \text { se asigna el número } 1\end{array}$ \\
\hline Escolaridad: hasta primaria $=1$ & $\begin{array}{l}\text { Dependientes económicos de } 3^{\mathrm{a}} \text { edad } \\
\text { (mayores de } 70 \text { años no trabajando })=1\end{array}$ & $\begin{array}{l}\text { Estados federativos de alto crecimiento: cuando } \\
\text { la tasa de crecimiento del PIB es mayor o igual } \\
\text { a } 9,04\end{array}$ \\
\hline $\begin{array}{l}\text { Escolaridad: } 1^{\circ} \text { de secundaria a } \\
3^{\circ} \text { de secundaria }=1\end{array}$ & \multicolumn{2}{|l|}{ Casado/a $=1$} \\
\hline Escolaridad: preparatoria = 1 & \multicolumn{2}{|l|}{ Soltero/a $=1$} \\
\hline Escolaridad: licenciatura y posgrado & \multicolumn{2}{|l|}{ Unión libre = 1} \\
\hline Localidad >100 000 habitantes $=1$ & \multicolumn{2}{|l|}{ Divorciado/a $=1$} \\
\hline & \multicolumn{2}{|l|}{ Viudo $/ \mathrm{a}=1$} \\
\hline
\end{tabular}

Fuente: elaboración propia.

PIB: producto interno bruto.

\section{Resultados de la estimación del modelo}

Se estimaron cuatro regresiones multilogísticas, una para las mujeres y otra para los hombres respecto de cada año. En cada regresión se obtuvieron resultados para las cuatro modalidades. El número de observaciones fue de 78.279 en 2005 y 75.950 en 2010 para las mujeres, y de 64.116 en 2005 y 59.342 en 2010 para los hombres ${ }^{10}$ que se refieren a los jefes/as o esposos/as en cada hogar. A fin de evitar posibles sesgos que pueden derivar de la heterogeneidad de los individuos, los errores estándar se estimaron con el método de Huber y White (Huber,

10 El programa STATA, con que se hicieron las estimaciones, elimina la observación en el caso de que algunas variables no tengan la información completa. Véase Stata User's Guide, Release 12 [en línea].
1967; White, 1982; Langlois, 1995) conocido como método robusto.

Los resultados fueron satisfactorios con excepción de la regresión de los hombres en 2005. La pseudo $\mathrm{R}^{2}$ del modelo multilogístico, que mide la relación entre el valor verosimilitud del modelo total frente al restringido con solo la constante de 2005 y 2010 , fue de $9,3 \%$ en ambos años para las mujeres y de 3,6\% para los hombres en 2005 y de $15,7 \%$ en 2010 . Los coeficientes en conjunto resultaron estadísticamente significativos en las cuatro regresiones de acuerdo con el estadístico de Wald. Debido a que se trata de un modelo no lineal, la interpretación de los coeficientes no es directa. Por ejemplo, un coeficiente positivo no implica necesariamente un aumento en la probabilidad. Por lo tanto, aquí se presentan los resultados sobre los efectos marginales que implican el cambio en la probabilidad debido a la modificación en una unidad 
de las variables independientes. Estos resultados se presentan en los cuadros 6 y $7^{11}$.

\section{a) Salario de reserva}

En términos de escolaridad, la variable de educación media y superior se relaciona negativamente con la probabilidad de decidirse por el trabajo manufacturero en el hogar, tanto para ellas como para ellos en ambos años, lo que indica que esa ocupación tiene un bajo salario de reserva por ser poco tecnificada. De manera similar en los servicios, el efecto marginal en la probabilidad del trabajo desde el domicilio es negativo para las jefas de hogar con mayor educación, con licenciatura o posgrado, en ambos años (efectos marginales de $-1,0$ en 2005 y $-1,2$ en 2010). Pero, a diferencia de las mujeres, hay mayor probabilidad de que los hombres más educados trabajen en su vivienda en los servicios en los dos años. Así, los efectos marginales en la probabilidad de ocuparse bajo esa modalidad fueron de 0,03 y 0,08 para preparatoria y de 0,65 y 0,43 para profesional. En este último caso puede considerarse que se trata de un nicho de alto valor agregado (consultorías, desempeño profesional: arquitectos, doctores, abogados, y servicios de tecnologías de la información, entre otros) que podría explicarse tanto por la subcontratación de servicios y el trabajo por cuenta propia, como por la presencia de trabajo virtual en casa para una empresa, como se expuso anteriormente.

En cuanto a la probabilidad del trabajo fuera del hogar, existe una vinculación negativa entre los niveles bajos de escolaridad, pero se aprecia notoriamente que en el caso de las mujeres estas tienen mayor probabilidad de elegir trabajar fuera del hogar cuando cuentan con educación profesional (efectos marginales de 22,54 y 19,33 ) o preparatoria $(9,48$ y 9,34 en los dos años), si bien con una tendencia ligeramente decreciente entre 2005 y 2010. Lo anterior no sucede con los jefes de hogar, ya que los efectos marginales son más pequeños o negativos: de $-3,87$ y 1,38 para licenciatura y de -1,63 y 1,39 para preparatoria. Esto confirma el valor de una alta escolaridad para las mujeres encontrado en otros trabajos (García y Pacheco, 2000) y sugiere que mientras los hombres consideran otros aspectos en la decisión de trabajar fuera del hogar, en el caso de ellas contar con educación superior es una variable relevante para elegir estas ocupaciones.

Fuera de la fuerza de trabajo, llaman la atención los altos efectos marginales positivos de los hombres

\footnotetext{
11 En el anexo se encuentran los resultados de las estimaciones.
}

con preparatoria y licenciatura en 2005 (2,03 y 4,65), lo que no ocurre en 2010 en la licenciatura, aunque con un efecto marginal muy pequeño, debido quizás a que buscaron ubicarse en opciones de menor ingreso. En cambio, se ratifica la hipótesis de que son las mujeres con baja escolaridad las desempleadas. Mientras que el efecto marginal de estar en primaria es en promedio de 3,6 , el de tener licenciatura y posgrado es de $-20,26$, es decir, que a mayor escolaridad menor es la probabilidad de estar desempleada (véanse los cuadros 6 y 7).

Tal como se esperaba, los resultados de las regresiones para el trabajo en el hogar de hombres y mujeres muestran una relación no lineal con la edad tanto en 2005 como en 2010. Esto ocurre en las tres opciones que se están analizando. Sin embargo, hay algunos matices a destacar. Por una parte, el efecto marginal de la edad en la probabilidad del trabajo desde el domicilio es más pronunciado en las jefas de hogar, es decir, estas tienden a laborar en el mercado con mayor edad. Por otra, en los años en estudio se aprecia un incremento en la probabilidad de trabajo con mayor edad, siendo particularmente notorio el caso de las jefas de hogar. Aquí hay dos excepciones: los jefes de hogar que trabajan desde el domicilio en la manufactura, cuyo efecto marginal en la probabilidad disminuye de 0,08 a 0,06 , y las mujeres que laboran en los servicios (de 0,28 a 0,26 ).

En los desempleados la edad hace disminuir la probabilidad de estar desempleado con más celeridad en 2010 que en 2005, mientras que en las mujeres no se da este cambio. En contraste, en las mujeres el desempleo tiende a aumentar con mayor velocidad que en los hombres a partir del punto de inflexión. Al visualizar a los hombres como únicos proveedores económicos del hogar, puede interpretarse que ellos como adultos mayores sean quienes deban generar ingresos en respuesta a las necesidades y demandas de los integrantes de su núcleo residencial (Millán, 2010).

En cuanto a los costos de desplazamiento, la probabilidad de que las mujeres trabajen desde su hogar en el sector manufacturero se relaciona de manera negativa con el mayor grado de urbanización, ligeramente inferior en 2010 que en 2005 (efectos marginales de $-1,40$ y -1,35). Para los hombres esta variable fue significativa solo en 2010 con un nivel más pequeño $(-0,11)$. Esto sugiere que las jefas de hogar que viven en zonas menos urbanizadas valoran no tener que desplazarse a trabajar fuera de sus hogares y también puede ser que les lleven el material de trabajo a su casa, como ocurre en la industria del vestido, o se trata de labores de artesanía autóctona. A diferencia del trabajo desde 
el domicilio en la industria, en los servicios este tiene lugar respecto de los dos años bajo estudio en zonas de mayor urbanización, con más de 100.000 habitantes, tanto para las mujeres (efectos marginales de $0,38 \mathrm{y}$ 0,37 ) como para los hombres $(0,40$ y 0,32$)$, aunque con un descenso en 2010 (véanse los cuadros 6 y 7).

Con respecto al efecto en la probabilidad de que las jefas de hogar trabajen fuera de su domicilio, en estas zonas es más elevado y con un incremento en 2010 (3,88 y 7,23). Para los jefes de hogar el efecto es positivo en $2005(3,18)$, pero negativo en $2010(-2,41)$. Una posible causa es que el desempleo masculino después de la crisis haya sido más alto en zonas de mayor urbanización. Finalmente, para las mujeres la probabilidad de vivir en zonas de poca urbanización aumenta la probabilidad de estar fuera de la fuerza de trabajo; algo similar sucede con los hombres en 2005, pero no en 2010.

\section{b) Costos fijos laborales}

La presencia de hijos pequeños (menores de ocho años) no afecta a la probabilidad de las jefas de hogar de trabajar en su vivienda en la manufactura y prácticamente tampoco en los servicios $(0,32)$ en 2010. En contraste, dicha presencia disminuye esa probabilidad en trabajos fuera de casa casi 20 veces más en 2005 y 2010 (-5,23 y $-6,17)$. Así, la probabilidad de estar desempleada teniendo hijos pequeños es muy alta en los dos años en estudio (5,13 y 5,76). En el caso de los hombres se obtienen efectos marginales no significativos tanto en manufactura como en servicios. No se encuentra un patrón para el efecto de esta variable en la probabilidad del trabajo fuera del domicilio y fuera de la fuerza laboral, ya que estos solo fueron estadísticamente significativos en 2010 , negativo en un caso $(-0,73)$ y positivo en el otro $(0,64)$. Por lo tanto, se confirma que la presencia de niños pequeños restringe la incorporación de las mujeres en el mercado de trabajo, pero no necesariamente en el trabajo desde el hogar. A diferencia de García y De Oliveira (1994), no se encuentra evidencia de que la dificultad de trabajar cuando hay hijos pequeños disminuya en un contexto de adversidad económica.

En lo referido a los hijos de 8 a 12 años de edad, se obtuvo para el caso de las mujeres el resultado esperado en el sentido de que estos son compatibles con el trabajo desde el hogar de manufactura y servicios en 2005 y 2010, y que solo parecen ser un obstáculo para laborar fuera del domicilio en 2005, lo que sugiere que el efecto de la crisis propició el ingreso de ellas al mercado de trabajo; así, la probabilidad de estar desempleadas disminuye $(-0,90)$ por esta razón. En los hombres nuevamente se encuentran resultados estadísticamente significativos. La discrepancia entre los efectos marginales mayores para ellas y menores para ellos corrobora el hecho de que finalmente el cuidado de los hijos recae en las mujeres.

En relación con la responsabilidad de tener una relación de pareja y su vinculación con la probabilidad del trabajo desde el hogar y fuera de este se vuelven a encontrar diferencias sustanciales de género. Los efectos marginales resultaron negativos en ambos años en estudio para las jefas de hogar casadas o bajo un acuerdo de unión libre, con mayor fuerza en el trabajo fuera del hogar (-20,1 y $-16,5$, respectivamente, en promedio) y entre las desempleadas (21,5 y 18,0 en promedio). No se encuentra relación entre las mujeres solas y la probabilidad del trabajo desde el hogar, pero sí con el trabajo fuera del domicilio. Puede decirse, entonces, que no tener una pareja eleva la tasa de participación de las mujeres en el mercado laboral. En los hombres estas variables resultaron no significativas en la mayoría de los casos como era de esperarse (véanse los cuadros 6 y 7 ).

\section{c) Entorno macroeconómico}

Por último, el entorno económico en que se desarrolla esta actividad — representado en el modelo adoptado en este estudio por el crecimiento del PIB de los estados donde se ubican estas actividades - tiene un efecto marginal positivo en la probabilidad del trabajo manufacturero desde el domicilio de las jefas de hogar en las entidades federativas de bajo crecimiento, aunque inferior en las de crecimiento medio. Esto sugiere que una parte del trabajo desde el domicilio constituye un refugio ante la ausencia de otras fuentes laborales. Si fuera un trabajo de subcontratación, este no debería estar circunscrito a estados de bajo crecimiento, sino al contrario.

En el caso de los servicios, solo fue significativo en las mujeres en los estados federativos de medio crecimiento, si bien con menor efecto marginal que en la manufactura. En cambio estos patrones no se observan en los hombres, donde tienen un efecto marginal negativo vinculado a la probabilidad de trabajar en los servicios desde la vivienda en los estados federativos de bajo crecimiento, lo que sugiere que buena parte de esta modalidad se realiza en estados de alto crecimiento y que puede originarse por subcontratación externa (outsourcing), o la presencia de oficina en la casa. Para las mujeres la probabilidad de trabajar fuera del domicilio también es mayor en las entidades federativas de bajo crecimiento que en las de medio. Lo opuesto ocurre en el caso de los hombres, donde la probabilidad de emplearse fuera del domicilio 


\begin{tabular}{|c|c|c|c|c|c|c|c|c|}
\hline & \multicolumn{2}{|c|}{$\begin{array}{l}\text { Desde domicilio } \\
\text { en manufactura }\end{array}$} & \multicolumn{2}{|c|}{$\begin{array}{l}\text { Desde domicilio } \\
\text { en servicios }\end{array}$} & \multicolumn{2}{|c|}{ Fuera del domicilio } & \multicolumn{2}{|c|}{$\begin{array}{c}\text { Fuera de la fuerza } \\
\text { de trabajo }\end{array}$} \\
\hline & 2005 & 2010 & 2005 & 2010 & 2005 & 2010 & 2005 & 2010 \\
\hline Primaria & 0,09 & 0,11 & $-0,15^{*}$ & 0,37 & $-3,67 * * *$ & $-4,08 * * *$ & $3,73 * * *$ & $3,60 * * *$ \\
\hline Preparatoria & $-0,63 * *$ & $-0,57 * * *$ & $-0,31$ & $-0,40$ & $9,48 * * *$ & $9,34 * * *$ & $-8,55 * * *$ & $-8,37 * * *$ \\
\hline Licenciatura y posgrado & $-1,27 * * *$ & $-1,17 * * *$ & $-1,0$ & $-1,23 * * *$ & $22,54 * * *$ & $19,33 * * *$ & $-20,26 * * *$ & $-16,93 * * *$ \\
\hline Edad & $0,13 * * *$ & $0,14 * * *$ & $0,28 * * *$ & $0,26 * * *$ & $3,85 * * *$ & $4,00 * * *$ & $-4,26 * * *$ & $-4,40 * * *$ \\
\hline Edad $^{2}$ & $0,00 * * *$ & $0,00 * * *$ & $0,00 * * *$ & $0,00 * * *$ & $-0,05 * * *$ & $-0,05 * * *$ & $0,05^{* * *} *$ & $0,06 * * *$ \\
\hline Localidad & $-1,41 * * *$ & $-1,35 * * *$ & $0,38 * * *$ & $0,37 * *$ & $3,88 * * *$ & $7,23 * * *$ & $-2,85^{* * * *}$ & $-6,24 * * *$ \\
\hline Hijos hasta 7 años & 0,05 & 0,32 & $0,04 * *$ & 0,1 & $-5,23 * * *$ & $-6,17 * * *$ & $5,13^{* * * *}$ & $5,76 * * *$ \\
\hline Hijos de 8 a 12 años & $0,23 * * *$ & $0,38 * * *$ & 0,15 & $0,28 *$ & $-0,65^{* *}$ & 0,24 & 0,27 & $-0,90 * *$ \\
\hline Unión libre & $-0,45^{* *}$ & $-0,41^{*}$ & $-1,20 * * *$ & $-0,91 * * *$ & $-16,26 * * *$ & $-16,80 * * *$ & $17,91 * * *$ & $18,13 * * *$ \\
\hline Casada & $0,56^{* * * *}$ & $-0,15^{* * *} *$ & $-1,19 * * *$ & $-0,90 * * *$ & $-20,12 * * *$ & $-20,25 * * *$ & $21,87 * * *$ & $21,30 * * *$ \\
\hline Separada & 0,45 & 0,39 & $1,80 * * *$ & 0,37 & $11,51 * * *$ & $10,16^{* * * *}$ & $-13,76 * * *$ & $-10,91 * * *$ \\
\hline Soltera & 0,32 & 0,38 & $1,10 * *$ & 0,18 & $14,72 * * *$ & $14,41 * * *$ & $-16,13 * * *$ & $-14,96 * * *$ \\
\hline Estado federativo de bajo crecimiento & $0,30 * *$ & $0,43 * * *$ & $-0,03$ & 0,23 & $1,99 * * *$ & $2,88 * * *$ & $-2,25 * * *$ & $-3,53 * * *$ \\
\hline Estado federativo de medio crecimiento & $1,60 * * *$ & $1,61 * * *$ & $1,70 * * *$ & $1,30 * * *$ & $1,15^{* *}$ & $1,08 * *$ & $-4,45 * * *$ & $-3,99 * * *$ \\
\hline
\end{tabular}

Fuente: estimaciones realizadas sobre la base de información de la Encuesta Nacional de Ocupación y Empleo (ENOE) y del Instituto Nacional de Estadística y Geografía (INEGI).

Nota: $\mathrm{p}^{* * *}<0,01 ; \mathrm{p}^{* *}<0,05 ; \mathrm{p}^{*}<0,10$.

CUADRO 7

Efectos marginales de las estimaciones, hombres: 2005 y 2010

\begin{tabular}{|c|c|c|c|c|c|c|c|c|}
\hline & \multicolumn{2}{|c|}{$\begin{array}{l}\text { Desde el domicilio } \\
\text { en manufactura }\end{array}$} & \multicolumn{2}{|c|}{$\begin{array}{c}\text { Desde el domicilio } \\
\text { en servicios }\end{array}$} & \multicolumn{2}{|c|}{ Fuera del domicilio } & \multicolumn{2}{|c|}{$\begin{array}{c}\text { Fuera de la fuerza } \\
\text { de trabajo }\end{array}$} \\
\hline & 2005 & 2010 & 2005 & 2010 & 2005 & 2010 & 2005 & 2010 \\
\hline Primaria & 0,17 & 0,04 & $-0,08$ & $-0,19$ & $-1,45 * * *$ & $-0,91 * * *$ & $1,36 * * *$ & $1,05 * * *$ \\
\hline Preparatoria & $-0,43 * *$ & $-0,24$ & $0,03 *$ & $0,08^{*}$ & $-1,63 * * *$ & $1,39 * * *$ & $2,03 * * *$ & $-1,23^{* * *}$ \\
\hline Licenciatura y posgrado & $-1,43 * * *$ & $-0,97 * * *$ & $0,65 * * *$ & $0,43 * * *$ & $-3,87 * * *$ & $1,38 * * *$ & $4,65 * * *$ & $-0,84 * *$ \\
\hline Edad & $0,08 * * *$ & $0,06 * * *$ & $0,04 * *$ & $0,11 * * *$ & $0,29 * * *$ & $0,42 * * *$ & $-0,41 * * *$ & $-0,58 * * *$ \\
\hline Edad $^{2}$ & $0,00 * * *$ & $0,00 *$ & $0,00 * * *$ & $0,00 * * *$ & $-0,01 * * *$ & $-0,01 * * *$ & $0,01 * * *$ & $0,01 * * *$ \\
\hline Localidad & $-0,01$ & $-0,11 * * *$ & $0,40 * *$ & 0,32 & $3,18 * * *$ & $-2,41 * * *$ & $-3,57 * * *$ & $2,20 * * *$ \\
\hline Hijos hasta 7 años & $-0,02$ & 0,13 & $-0,06$ & $-0,04$ & $-0,1$ & $-0,73 * * *$ & 0,18 & $0,64 * * *$ \\
\hline Hijos de 8 a 12 años & 0,01 & 0,05 & 0,06 & 0,02 & $-0,4$ & $1,19 * * *$ & $0,33 *$ & $-1,26 * * *$ \\
\hline Unión libre & 0,08 & 0,35 & 0,57 & 0,29 & $-5,16^{* * *}$ & 0,07 & $4,51 * * *$ & $-0,7$ \\
\hline Casado & 0,01 & 0,46 & 0,24 & $-0,07$ & $-1,29$ & 0,65 & 1,03 & $-1,03$ \\
\hline Separado & $-0,04$ & 1,97 & 0,81 & 1,75 & $-3,27 * *$ & $-1,43$ & 2,51 & $-2,29$ \\
\hline Soltero & 0,13 & $-0,26$ & $-0,27$ & $-0,54$ & 1,07 & 0,92 & $-0,94$ & $-0,13$ \\
\hline Estado federativo de bajo crecimiento & $-0,11$ & $-0,06$ & $-0,25 *$ & $-0,25 * *$ & $-1,92 * * *$ & $-0,05$ & $2,27 * * *$ & 0,36 \\
\hline Estado federativo de medio crecimiento & 0,08 & $0,19 *$ & $-0,1$ & 0,03 & $-3,66^{* * * *}$ & $1,14 * * *$ & $3,69 * * *$ & $-1,37 * * *$ \\
\hline
\end{tabular}

Fuente: estimaciones realizadas sobre la base de información de la Encuesta Nacional de Ocupación y Empleo (ENOE) y del Instituto Nacional de Estadística y Geografía (INEGI).

Nota: $\mathrm{p}^{* * *}<0,01 ; \mathrm{p}^{* *}<0,05 ; \mathrm{p}^{*}<0,10$. 
es negativa en los estados federativos de bajo crecimiento en los dos años, mientras que en los de medio crecimiento fue negativo en 2005 y positivo en 2010. Finalmente, la probabilidad de desempleo parece vincularse en las mujeres a los estados de alto crecimiento y lo contrario sucede en el caso de los hombres.

Estos resultados aluden al efecto de las condiciones económicas adversas. Una explicación posible es que en este contexto macroeconómico negativo las mujeres tienen una mayor necesidad de salir a trabajar para complementar el ingreso de sus hogares, tanto por la falta de oportunidades de trabajo, como por la migración a los Estados Unidos de América de sus esposos e hijos ${ }^{12}$. Por el contrario, los resultados que atañen a los hombres sugieren que el crecimiento económico propicia la subcontratación y la demanda de consultorías y que el trabajo desde el hogar no necesariamente es un refugio ante oportunidades insuficientes de empleo.

\footnotetext{
12 De 12 estados federativos de bajo crecimiento, 6 forman parte del grupo de estados con mayor migración.
}

\section{V}

\section{Consideraciones finales}

Si bien subsisten formas laborales que datan de la revolución industrial, donde están presentes las condiciones de los talleres en que se explota a los trabajadores (sweat-shops) analizadas en El Capital de Marx, también es cierto que los entornos y el sitio de trabajo están experimentando cambios importantes con el trabajo virtual y las oficinas en el hogar, entre otros. A lo largo de este estudio se ha mostrado que el trabajo desde el domicilio es una modalidad laboral compleja, resultado de múltiples factores. Su explicación no solo radica en la creciente demanda de trabajo flexible en condiciones de costos menores para lograr ahorros en tiempo y espacio, o en el desarrollo de las tecnologías de la información que facilitan el monitoreo del trabajo en el hogar, sino que es necesario - sobre todo en el caso de las mujeres - considerar las relaciones de género de carácter patriarcal, que inciden en la limitación que tienen las mujeres para laborar en el mercado en situación de igualdad con los hombres.

Los hallazgos de este estudio muestran que hay grandes diferencias de género en los factores que subyacen a las decisiones de trabajar desde el domicilio, fuera de este o bien permanecer al margen de la fuerza de trabajo. En otras palabras, es una evidencia más en el sentido de que el mercado laboral no es neutro en cuestiones de género, ya que hay normas informales y culturales que determinan la segregación de género en ciertos sectores de la economía y modalidades de trabajo, así como la segregación vertical tal como se señala en la economía feminista.

Las diferencias entre jefes y jefas de hogar se hacen más evidentes, como era de esperar, debido a la presencia de hijos, lo que incrementa la probabilidad de trabajar desde el domicilio, tanto en la manufactura como en los servicios, y disminuye la de laborar fuera del hogar entre las mujeres. Es decir, el trabajo desde el domicilio es funcional a la presencia de hijos y dificulta la participación femenina para ocuparse en otros sitios, lo que hace evidente la insuficiencia de escuelas y guarderías con horarios adecuados para que las madres puedan tener distintas opciones laborales. Más aún, se esperaba que con el aumento de la participación femenina en la fuerza de trabajo en las últimas dos décadas el matrimonio no fuera un impedimento para que se sumaran a ella; empero, los resultados sobre la relación negativa de la condición de ser casada o tener una relación de pareja y el trabajo desde el hogar o fuera de este sugieren que se está lejos de ello. Son las mujeres solas, solteras, separadas o divorciadas las que en cambio tienen una alta probabilidad de participar en la fuerza de trabajo.

De esta manera, se confirma la opinión de Kantor (2000) de que el trabajo desde el domicilio es una oportunidad para que las mujeres trabajen y ganen un ingreso sin cuestionar la ideología patriarcal. En contraste, en los hombres estas variables no fueron significativas. El ocuparse en su domicilio le da a la mujer la oportunidad de entrar al mercado en condiciones de flexibilidad de horarios y localización y combinar el trabajo doméstico con el que se realiza para el mercado. En el caso de los hombres, hay otros factores más importantes detrás de esta decisión. Estos resultados confirman las conclusiones de Rani y Unni (2009) y de Edwards y Field-Hendrey (2002).

En cuanto a la segmentación de género en la distribución espacial del trabajo manufacturero desde el domicilio, las altas probabilidades de realizarlo en zonas de menor urbanización e incluso rurales (solo en 
el caso de las mujeres) sugiere, además de lo señalado, que entre ellas hay una mayor proporción de quienes desempeñan labores artesanales autóctonas, lo que también requiere investigarse más a fondo. Llama la atención que la probabilidad de trabajar fuera del hogar en zonas de alta urbanización fuera negativa en 2010 para los hombres, lo que sugiere que el efecto de la crisis en el empleo afectó más a los hombres en zonas urbanas.

Asimismo, se corrobora la presencia de un bajo salario de reserva del trabajo desde el domicilio para las mujeres, tanto en los servicios como en la manufactura, y que la probabilidad de laborar en esa modalidad se eleva cuando se tienen niveles menores que la educación secundaria. Entre los hombres que se ocupan en el sector manufacturero sucede lo mismo, pero no en los servicios, donde la probabilidad es alta cuando se cuenta con nivel profesional y posgrado. No es posible determinar si esto forma parte de la tendencia de los profesionales de la salud a dar atención en sus hogares, lo que siempre ha sucedido, o bien que ha aumentado el número de profesionales desempleados que inician negocios en casa o recurren a las nuevas modalidades de trabajo con tecnologías de la información. Además de esta interrogante, surge otra: ¿por qué si hay mujeres profesionales, estas tienden a participar solo fuera del domicilio? Esta es una línea de investigación abierta.

Por último, si se acepta que el crecimiento del PIB es un indicador de las condiciones del entorno económico, se aprecia que tanto los hombres como las mujeres tienen mayores probabilidades de trabajar desde su hogar en estados federativos de crecimiento medio. Sin embargo, un resultado sorprendente fue que las mujeres tienen mayor probabilidad de participar en el mercado de trabajo en estados de bajo crecimiento en cualquiera de las modalidades analizadas, mientras que lo contrario sucede con los hombres debido quizás a la necesidad de ellas de salir a laborar para complementar el ingreso de sus hogares, tanto debido a la falta de oportunidades de trabajo, como a la migración a los Estados Unidos de América de sus esposos e hijos. Al contrario, los resultados respecto de los hombres sugieren que el crecimiento favorece la subcontratación, así como la demanda de consultorías, y que el trabajo desde el domicilio es un complemento y no un paliativo cuando las oportunidades de empleo son escasas.

Los resultados obtenidos para la variable fuera del domicilio evidencian las dificultades que hoy día enfrentan las mujeres casadas y con hijos para emplearse en esta modalidad y que las medidas de política pública han sido insuficientes para contrarrestarlas.

Con relación al efecto de la crisis, los resultados de este trabajo sugieren que esta afectó agudamente al empleo de la población trabajadora, en particular al trabajo desde el domicilio para el sector manufacturero, el que sufrió una fuerte caída que puede deberse en parte al descenso en la demanda de productos a subcontratación, tales como muebles, ropa de confección y productos metálicos. Lo anterior ocurrió con mayor profundidad entre los jefes de hogar, que pasaron a aumentar su participación en el trabajo desde el domicilio en los servicios como opción de empleo.

En relación con otros factores que explican la decisión de jefes y jefas de hogar de trabajar desde su vivienda, debe mencionarse que la tendencia a la participación con más edad en este tipo de ocupación sugiere que existe una mayor necesidad de autoemplearse dado el incremento del desempleo ocasionado por la crisis.

Por último, la responsabilidad de pareja continuó siendo un obstáculo para trabajar; sin embargo, en los resultados de este estudio se aprecia que en 2010 dicho obstáculo era menor, lo que indica que la repercusión de la crisis en el empleo y el ingreso propicia que las mujeres consideren participar en el mercado laboral. Asimismo, se advierte la dificultad de los jefes de hogar para emplearse en las zonas urbanas en 2010.

Se puede afirmar que el trabajo desde el domicilio tiene como ventaja la generación de ingreso. No obstante, los presentes resultados resaltan el bajo salario que involucra esta modalidad. Así, se confirma el planteamiento de Atasü Topçuoglu (2005) y Hartmann (1979) en lo que se refiere a la posición de las mujeres en el mercado laboral. Por una parte, estas obtienen bajos salarios en el mercado y son por ello dependientes de los de sus esposos, por lo cual deben realizar el trabajo doméstico. A la vez, sus responsabilidades hogareñas debilitan su posición en el mercado, lo que redunda en menores salarios comparados con los de los hombres. Más aún, como mencionan Kabeer, Mahmud y Tasneem (2011), el salario no necesariamente es suficiente para el empoderamiento de la mujer. Una línea de investigación futura consiste en examinar esta cuestión para el caso del trabajo desde el domicilio en México.

De los resultados del presente estudio se puede inferir que el trabajo desde el hogar seguirá siendo importante para las mujeres y crecientemente para los hombres. De aquí la necesidad de reflexionar sobre una legislación en que se reconozcan los derechos de los trabajadores informales y una política social que mejore las condiciones en que este trabajo se realiza, con la inclusión de acceso a la salud y seguridad social, programas de capacitación e incluso el replanteamiento de las políticas de vivienda social que han ignorado las necesidades del trabajo desde el hogar. 
ANEXO

CUADRO A.1

Resultados de las regresiones: mujeres

\begin{tabular}{|c|c|c|c|c|c|c|}
\hline & \multicolumn{3}{|c|}{$\begin{array}{c}2005 \\
\mathrm{~N}^{\mathrm{o}} \text { observaciones: } 78279 \\
\text { Pseudo R } 2 \text { 9,3\%, Prob. Wald 0,00 }\end{array}$} & \multicolumn{3}{|c|}{$\begin{array}{c}2010 \\
\mathrm{~N}^{\mathrm{o}} \text { observaciones: } 75950 \\
\text { Pseudo } \mathrm{R}^{2} \text { 9,3\%, Prob. Wald 0,00 }\end{array}$} \\
\hline & \multicolumn{2}{|c|}{ Trabajo desde el domicilio } & \multirow{2}{*}{$\begin{array}{l}\text { Trabajo fuera } \\
\text { del domicilio }\end{array}$} & \multicolumn{2}{|c|}{ Trabajo desde el domicilio } & \multirow{2}{*}{$\begin{array}{l}\text { Trabajo fuera } \\
\text { del domicilio }\end{array}$} \\
\hline & Manufactura & Servicios & & Manufactura & Servicios & \\
\hline Primaria & $\begin{array}{l}-0,013 \\
(0,055)\end{array}$ & $\begin{array}{l}-0,104 * * \\
(0,047)\end{array}$ & $\begin{array}{l}-0,170 * * * \\
(0,020)\end{array}$ & $\begin{array}{l}-0,001 \\
(0,059)\end{array}$ & $\begin{array}{c}0,053 \\
(0,050)\end{array}$ & $\begin{array}{l}-0,174^{* * * *} \\
(0,021)\end{array}$ \\
\hline Preparatoria & $\begin{array}{l}-0,243^{* *} \\
(0,114)\end{array}$ & $\begin{array}{c}0,060 \\
(0,076)\end{array}$ & $\begin{array}{l}0,403^{* * *} \\
(0,030)\end{array}$ & $\begin{array}{l}-0,210 * * * \\
(0,102)\end{array}$ & $\begin{array}{c}0,021 \\
(0,078)\end{array}$ & $\begin{array}{l}0,384^{* * * *} \\
(0,027)\end{array}$ \\
\hline Licenciatura y posgrado & $\begin{array}{l}-0,481 * * * \\
(0,095)\end{array}$ & $\begin{array}{c}0,063 \\
(0,060)\end{array}$ & $\begin{array}{l}0,947 * * * \\
(0,023)\end{array}$ & $\begin{array}{l}-0,471^{* * *} \\
(0,096)\end{array}$ & $\begin{array}{l}-0,123 * * * \\
(0,067)\end{array}$ & $\begin{array}{l}0,784^{* * * *} \\
(0,023)\end{array}$ \\
\hline Edad & $\begin{array}{l}0,138^{* * * *} \\
(0,014)\end{array}$ & $\begin{array}{l}0,149^{* * *} \\
(0,012)\end{array}$ & $\begin{array}{l}0,184^{* * * *} \\
(0,006)\end{array}$ & $\begin{array}{l}0,155^{* * *} \\
(0,015)\end{array}$ & $\begin{array}{l}0,158^{* * *} \\
(0,013)\end{array}$ & $\begin{array}{l}0,184^{* * * *} \\
(0,006)\end{array}$ \\
\hline Edad $^{2}$ & $\begin{array}{l}-0,002^{* * * *} \\
(0,000)\end{array}$ & $\begin{array}{l}-0,002 * * * \\
(0,000)\end{array}$ & $\begin{array}{l}-0,002^{* * * *} \\
(0,000)\end{array}$ & $\begin{array}{l}-0,002 * * * \\
(0,000)\end{array}$ & $\begin{array}{l}-0,002 * * * \\
(0,000)\end{array}$ & $\begin{array}{l}-0,002 * * * \\
(0,000)\end{array}$ \\
\hline Localidad & $\begin{array}{l}-0,706^{* * * *} \\
(0,053)\end{array}$ & $\begin{array}{l}0,152 * * * \\
(0,042)\end{array}$ & $\begin{array}{l}0,162^{* * * *} \\
(0,018)\end{array}$ & $\begin{array}{l}-0,639 * * * \\
(0,055)\end{array}$ & $\begin{array}{l}0,224 * * \\
(0,045)\end{array}$ & $\begin{array}{l}0,303^{* * *} \\
(0,017)\end{array}$ \\
\hline Hijos hasta 7 años & $\begin{array}{l}-0,058 \\
(0,039)\end{array}$ & $\begin{array}{l}-0,072^{* *} \\
(0,031)\end{array}$ & $\begin{array}{l}-0,240 \text { *** } \\
(0,013)\end{array}$ & $\begin{array}{c}0,074 \\
(0,071)\end{array}$ & $\begin{array}{l}-0,067 \\
(0,063)\end{array}$ & $\begin{array}{l}-0,269 * * * \\
(0,022)\end{array}$ \\
\hline Hijos de 8 a 12 años & $\begin{array}{l}0,120^{* * * *} \\
(0,033)\end{array}$ & $\begin{array}{c}0,037 \\
(0,028)\end{array}$ & $\begin{array}{l}-0,024^{* *} \\
(0,012)\end{array}$ & $\begin{array}{l}0,215^{* * *} \\
(0,058)\end{array}$ & $\begin{array}{c}0,103^{*} \\
(0,050)\end{array}$ & $\begin{array}{l}0,022^{* *} \\
(0,019)\end{array}$ \\
\hline Unión libre & $\begin{array}{l}-0,532^{* *} \\
(0,125)\end{array}$ & $\begin{array}{l}-0,628 * * * \\
(0,105)\end{array}$ & $\begin{array}{l}-0,777 * * * \\
(0,046)\end{array}$ & $\begin{array}{l}-0,541^{*} \\
(0,136)\end{array}$ & $\begin{array}{l}-0,602 * * * \\
(0,110)\end{array}$ & $\begin{array}{l}-0,766^{* * *} \\
(0,046)\end{array}$ \\
\hline Casada & $\begin{array}{l}-0,657 * * * \\
(0,105)\end{array}$ & $\begin{array}{l}-0,690 * * * \\
(0,088)\end{array}$ & $\begin{array}{l}-0,957 * * * \\
(0,041)\end{array}$ & $\begin{array}{l}-0,451 * * * \\
(0,115)\end{array}$ & $\begin{array}{l}-0,651 * * * \\
(0,093)\end{array}$ & $\begin{array}{l}-0,914 * * * \\
(0,041)\end{array}$ \\
\hline Divorciada & $\begin{array}{c}0,468 \\
(0,202)\end{array}$ & $\begin{array}{l}0,502 * * * \\
(0,150)\end{array}$ & $\begin{array}{l}0,577 * * * \\
(0,071)\end{array}$ & $\begin{array}{l}-0,022 \\
(0,244)\end{array}$ & $\begin{array}{c}0,181 \\
(0,163)\end{array}$ & $\begin{array}{c}0,364 * * * \\
(0,068) * * *\end{array}$ \\
\hline Separada & $\begin{array}{c}0,473 \\
(0,140)\end{array}$ & $\begin{array}{l}0,665^{* * *} \\
(0,110)\end{array}$ & $\begin{array}{l}0,551 * * * \\
(0,055)\end{array}$ & $\begin{array}{c}0,402 \\
(0,153)\end{array}$ & $\begin{array}{c}0,317 \\
(0,120)\end{array}$ & $\begin{array}{c}0,452 \\
(0,054)\end{array}$ \\
\hline Soltera & $\begin{array}{c}0,433 \\
(0,171) \\
(0,095)\end{array}$ & $\begin{array}{l}0,570 * * \\
(0,130) \\
(0,060)\end{array}$ & $\begin{array}{l}0,702 * * * \\
(0,063) \\
(0,023)\end{array}$ & $\begin{array}{c}0,467 \\
(0,169) \\
(0,096)\end{array}$ & $\begin{array}{c}0,314 \\
(0,136) \\
(0,067)\end{array}$ & $\begin{array}{l}0,647 * * * \\
(0,059) \\
(0,023)\end{array}$ \\
\hline $\begin{array}{l}\text { Estado federativo de bajo } \\
\text { crecimiento }\end{array}$ & $\begin{array}{l}0,193 * * \\
(0,080)\end{array}$ & $\begin{array}{l}0,028 \\
(0,057)\end{array}$ & $\begin{array}{l}0,096^{* * * *} \\
(0,022)\end{array}$ & $\begin{array}{l}0,289 * * * \\
(0,078)\end{array}$ & $\begin{array}{c}0,134 \\
(0,059)\end{array}$ & $\begin{array}{l}0,138 * * * \\
(0,021)\end{array}$ \\
\hline $\begin{array}{l}\text { Estado federativo de medio } \\
\text { crecimiento }\end{array}$ & $\begin{array}{l}0,838 * * * \\
(0,073)\end{array}$ & $\begin{array}{l}0,521 * * * \\
(0,052)\end{array}$ & $\begin{array}{l}0,108 * * * \\
(0,022)\end{array}$ & $\begin{array}{l}0,847 * * * \\
(0,073)\end{array}$ & $\begin{array}{l}0,458 * * * \\
(0,056)\end{array}$ & $\begin{array}{l}0,099 * * \\
(0,021)\end{array}$ \\
\hline Constante & $\begin{array}{l}-5,632 \\
(0,331)\end{array}$ & $\begin{array}{l}-5,391 \\
(0,271)\end{array}$ & $\begin{array}{l}-3,183 \\
(0,127)\end{array}$ & $\begin{array}{l}-6,351 \\
(0,358)\end{array}$ & $\begin{array}{l}-5,967 \\
(0,304)\end{array}$ & $\begin{array}{l}-3,169 \\
(0,124)\end{array}$ \\
\hline
\end{tabular}

Fuente: estimaciones realizadas sobre la base de información de la Encuesta Nacional de Ocupación y Empleo (ENOE) y del Instituto Nacional de Estadística y Geografía (INEGI).

Nota: $\mathrm{p}^{* * *}<0,01 ; \mathrm{p}^{* *}<0,05$. 
Resultados de las regresiones: hombres

\begin{tabular}{|c|c|c|c|c|c|c|}
\hline & \multicolumn{3}{|c|}{ 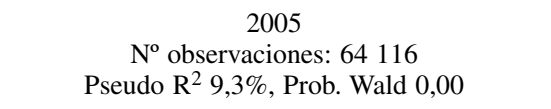 } & \multicolumn{3}{|c|}{ 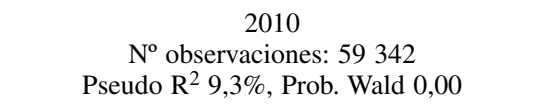 } \\
\hline & \multicolumn{2}{|c|}{ Trabajo desde el domicilio } & \multirow{2}{*}{$\begin{array}{l}\text { Trabajo fuera } \\
\text { del domicilio }\end{array}$} & \multicolumn{2}{|c|}{ Trabajo desde el domicilio } & \multirow{2}{*}{$\begin{array}{l}\text { Trabajo fuera } \\
\text { del domicilio }\end{array}$} \\
\hline & Manufactura & Servicios & & Manufactura & Servicios & \\
\hline \multirow[t]{2}{*}{ Primaria } & 0,118 & $-0,088$ & $-0,145^{* * *}$ & $-0,065$ & $-0,247$ & $-0,116^{* * *}$ \\
\hline & $(0,078)$ & $(0,102)$ & $(0,031)$ & $(0,094)$ & $(0,096)$ & $(0,034)$ \\
\hline \multirow[t]{2}{*}{ Preparatoria } & $-0,358 * *$ & $0,002^{*}$ & $-0,169 * * *$ & $-0,121 * *$ & $0,187^{*}$ & $0,148 * * *$ \\
\hline & $(0,123)$ & $(0,140)$ & $(0,039)$ & $(0,135)$ & $(0,124)$ & $(0,050)$ \\
\hline \multirow[t]{2}{*}{ Licenciatura y posgrado } & $-1,174 * * *$ & $0,536 * * *$ & $-0,399 * * *$ & $-1,145^{* * *}$ & $0,373 * * *$ & $0,104 * * *$ \\
\hline & $(0,131)$ & $(0,101)$ & $(0,035)$ & $(0,156)$ & $(0,100)$ & $(0,039)$ \\
\hline \multirow[t]{2}{*}{ Edad } & $0,066^{* * *}$ & $0,042 * * *$ & $0,030 * * *$ & $0,113 * * *$ & $0,139 * * *$ & $0,065^{* * *}$ \\
\hline & $(0,016)$ & $(0,018)$ & $(0,007)$ & $(0,023)$ & $(0,02)$ & $(0,008)$ \\
\hline \multirow[t]{2}{*}{$\mathrm{Edad}^{2}$} & $-0,001 * * *$ & $0,000 * *$ & $-0,001 * * *$ & $-0,002^{*}$ & $-0,002 * * *$ & $-0,001 * * *$ \\
\hline & $(0,000)$ & $(0,000)$ & $(0,000)$ & $(0,000)$ & $(0,000)$ & $(0,000)$ \\
\hline \multirow[t]{2}{*}{ Localidad } & 0,036 & $0,403 * *$ & $0,324 * * *$ & $-0,328$ & 0,003 & $-0,253^{* * *}$ \\
\hline & $(0,071)$ & $(0,087)$ & $(0,027)$ & $(0,0845)$ & $(0,082)$ & $(0,029)$ \\
\hline \multirow[t]{2}{*}{ Hijos hasta 7 años } & $-0,020$ & $-0,056$ & $-0,011$ & 0,061 & $-0,092$ & $-0,074 * * *$ \\
\hline & $(0,051)$ & $(0,065)$ & $(0,017)$ & $(0,066)$ & $(0,063)$ & $(0,027)$ \\
\hline \multirow[t]{2}{*}{ Hijos de 8 a 12 años } & 0,007 & 0,052 & $-0,040$ & 0,180 & $0,143^{* * *}$ & $0,143^{* * *}$ \\
\hline & $(0,046)$ & $(0,052)$ & $(0,017)$ & $(0,064)$ & $(0,060)$ & $(0,026)$ \\
\hline \multirow[t]{2}{*}{ Unión libre } & 0,013 & 0,390 & $-0,607 * * *$ & 0,402 & 0,283 & 0,073 \\
\hline & $(0,276)$ & $(0,306)$ & $(0,137)$ & $(0,356)$ & $(0,272)$ & $(0,081)$ \\
\hline \multirow[t]{2}{*}{ Casado } & 0,000 & 0,209 & $-0,127$ & 0,541 & 0,054 & 0,113 \\
\hline & $(0,258)$ & $(0,288)$ & $(0,132)$ & $(0,341)$ & $(0,259)$ & $(0,072)$ \\
\hline \multirow[t]{2}{*}{ Divorciado } & 0,862 & 0,536 & $-0,670 * * *$ & 0,413 & 0,094 & $-0,266$ \\
\hline & $(0,486)$ & $(0,581)$ & $(0,322)$ & $(0,679)$ & $(0,506)$ & $(0,182)$ \\
\hline \multirow[t]{2}{*}{ Separado } & $-0,063$ & 0,525 & $-0,372 * *$ & 1,331 & 1,086 & 0,250 \\
\hline & $(0,459)$ & $(0,464)$ & $(0,207)$ & $(0,453)$ & $(0,359)$ & $(0,152)$ \\
\hline \multirow[t]{2}{*}{ Soltero } & 0,111 & $-0,232$ & 0,106 & $-0,268$ & $-0,477$ & 0,023 \\
\hline & $(0,565)$ & $(0,756)^{* * *}$ & $(0,211)$ & $(1,072)$ & $(0,764)$ & $(0,224)$ \\
\hline \multirow{2}{*}{$\begin{array}{l}\text { Estado federativo de bajo } \\
\text { crecimiento }\end{array}$} & $-0,113$ & $-0,253 *$ & $-0,197 * *$ & $-0,096$ & $-0,223 * *$ & $-0,038$ \\
\hline & $(0,090)$ & $(0,094)$ & $(0,030)$ & $(0,110)$ & $(0,095)$ & $(0,035)$ \\
\hline \multirow{2}{*}{$\begin{array}{l}\text { Estado federativo de medio } \\
\text { crecimiento }\end{array}$} & 0,018 & $-0,137$ & $-0,369 * * *$ & $0,324^{*}$ & 0,165 & $0,155^{* * * *}$ \\
\hline & $(0,087)$ & $(0,091)$ & $(0,031)$ & $(0,106)$ & $(0,091)$ & $(0,035)$ \\
\hline \multirow[t]{2}{*}{ Constante } & $-5,348$ & $-5,926$ & $-1,289$ & $-4,053$ & $-4,405$ & 2,307 \\
\hline & $(0,476)$ & $(0,546)$ & $(0,195)$ & $(0,651)$ & $(0,576)$ & $(0,218)$ \\
\hline
\end{tabular}

Fuente: estimaciones realizadas sobre la base de información de la Encuesta Nacional de Ocupación y Empleo (ENOE) y del Instituto Nacional de Estadística y Geografía (INEGI).

Nota: $\mathrm{p}^{* * *}<0,01 ; \mathrm{p}^{* *}<0,05 ; \mathrm{p}^{*}<0,10$.

Bibliografía

Anderson, P.M. y P.B. Levine (1999), "Child care and mothers' employment decisions", JCPR Working Papers, $\mathrm{N}^{\circ}$ 64, Chicago, Northwestern University/University of Chicago Joint Center for Poverty Research.

Aroche, F. y M.E. Cardero (2007), "Cambio estructural comandado por apertura comercial. El caso de la economía mexicana", Estudios Económicos, vol. 23, $\mathrm{N}^{\circ}$ 2, México, D.F., Centro de Estudios Económicos, El Colegio de México.
Atasü Topçuoglu, R. (2005), "Home-based Work and Informal Sector in the Period of Globalisation: An Analysis Through Capitalism and Patriachy. The Case of Turkey", tesis, Ankara, The Graduate School of Social Sciences, Middle East Technical University.

Benería, L. (1981), "Gender and the dynamics of subcontracting in Mexico City", Gender in the Work Place, C. Brown y J.A. Pechman (eds.), Washington, D.C., The Brookings Institution. 
Benería, L. y M. Roldan (1992), Las encrucijadas de clase y género. Trabajo a domicilio, subcontratación y dinámica de la unidad doméstica en la Ciudad de México, México, D.F., El Colegio de México.

(1987), The Crossroads of Class and Gender: Industrial Homework, Subcontracting, and Household Dynamics in Mexico City, Chicago, The University of Chicago Press.

Benería, L. y otros (2000), "Globalization and gender", Feminist Economics, vol. 6, $\mathrm{N}^{\circ} 3$, Taylor \& Francis.

Bover, O. y M. Arellano (1995), "Female labour force participation in the 1980s: the case of Spain", Investigaciones Económicas, vol. 19, $\mathrm{N}^{\circ} 2$, Madrid, Fundación SEPI.

Çağatay, N. (2005), "Gender inequalities and international trade: a theoretical reconsideration", serie Seminarios y Talleres, $\mathrm{N}^{\circ}$ 136, Montevideo, Centro Interdisciplinario de Estudios sobre el Desarrollo (CIEDUR).

Cardero, M.E. y G. Espinosa (2013), "Empleo, empleo informal de hombres y mujeres e indicadores de pobreza", México, mujeres y economía, México, D.F., Facultad de Economía, Universidad Nacional Autónoma de México (UNAM).

Carr, M., A.M. Chen y J. Tate (2000), "Globalization and homebased workers", Feminist Economics, vol. 6, 우 3, Taylor \& Francis.

Cerda, M. (2011), "El 'home office' gana terreno en México", CNN Expansión [en línea] http://www.cnnexpansion.com/ opinion/2011/07/25/el-home-office-gana-terreno-en-mexico.

De Oliveira, O. y M. Eternod (2000), "La fuerza de trabajo en México: Un siglo de cambios", Cien años de demografía en México, J. Gómez de León y C. Rabell (eds.), México, D.F., Fondo de Cultura Económica.

Dedeoglu, S. (2010), "Visible hands - invisible women: garment production in Turkey", Feminist Economics, vol.16, $\mathrm{N}^{\circ} 4$, Taylor \& Francis.

Edwards, L. y E. Field-Hendrey (2002), "Home-based work and women's labor force decisions", Journal of Labor Economics, vol. 20, $\mathrm{N}^{\circ} 1$, Chicago, University of Chicago Press.

Elson, D. (1999), "Labor markets as gendered institutions: equality, efficiency and empowerment issues", World Development, vol. 27, $\mathrm{N}^{\circ} 3$, Amsterdam, Elsevier.

García, B. (2001), "Reestructuración económica y feminización del mercado de trabajo en México", Papeles de Población, vol. 7, $\mathrm{N}^{\circ}$ 27, Toluca, Universidad Autónoma del Estado de México (UnAm).

García, B. y E. Pacheco (2000), "Esposa, hijos e hijas en el mercado de trabajo de la Ciudad de México en 1995", Estudios Demográficos y Urbanos, vol. 15, $\mathrm{N}^{\circ} 1$, México, D.F., Centro de Estudios Demográficos, Urbanos y Ambientales, El Colegio de México.

García, B. y O. De Oliveira (1994), Trabajo femenino y vida familiar en México, México, D.F., El Colegio de México.

Gereffi, G., J. Humphrey y T. Sturgeon (2005), "The governance of global value chains", Review of International Political Economy, vol. 12, $\mathrm{N}^{\circ} 1$, Taylor \& Francis.

Hartmann, H. (1979), "The unhappy marriage of Marxism and feminism: towards a more progressive union", Capital and Class, vol. $3, \mathrm{~N}^{\circ} 2$, Sage.

Huber, P.J. (1967), "The behavior of maximum likelihood estimates under nonstandard conditions", Proceedings of the Fifth Berkeley Symposium on Mathematical Statistics and Probability, Berkeley, University of California Press.

Juárez, H. (2004), Allá donde viven los más pobres. Cadenas globales y regiones productoras en la industria del vestido, México, D.F., Universidad Obrera de México.
Kabeer, N., S. Mahmud y S. Tasneem (2011), "Does paid work provide a pathway to women's empowerment? Empirical findings from Bangladesh", IDS Working Paper, vol. 2011, $\mathrm{N}^{\circ} 375$, Brighton, Institute of Development Studies.

Kantor, P. (2003), Women's empowerment through home-based work: evidence from India, Development and Change, vol. 34, $\mathrm{N}^{\circ} 3$, Wiley.

(2000), Gender Differentials in Microenterprise Success for Homebased Garment Makers in Ahmedabad, Chapel Hill, University of North Carolina.

Knaul, F. y S.W. Parker (1997), "Estrategias de empleo y cuidado de los niños entre mujeres mexicanas con hijos pequeños", documento presentado en el II Seminario de investigación laboral: Participación de la mujer en el mercado laboral, México, D.F., Secretaría del Trabajo y Previsión Social.

Langlois, R. (1995), "The vanishing hand: the changing dynamics of industrial capitalism", Industrial and Corporate Change, vol. 12, $\mathrm{N}^{\circ}$ 2, Oxford, Oxford University Press.

López, E.S. (2005), "Trabajo a domicilio, pequeños talleres y precariedad laboral en Piedra Negras y Torreón", México, D.F., Instituto de Estudios del Trabajo.

Louw, E. y P. De Vries (2002), "Working at home: the Dutch property dimension", Planning Practice and Research, vol. 17, $\mathrm{N}^{\circ} 1$, Taylor \& Francis.

Maldonado, V. y T. Rendón (2004), "Vínculos entre trabajo doméstico, segregación ocupacional y diferencias de ingreso por sexo en el México actual", México, D.F., Instituto de Estudios del Trabajo.

Marx, Karl (1959), El capital, México, D.F., Fondo de Cultura Económica.

Millán, León Beatriz (2010), "Factores asociados a la participación laboral de los adultos mayores mexiquenses", Papeles de Población, vol. 16, $\mathrm{N}^{\circ}$ 64, Toluca, Universidad Autónoma del Estado de México.

Ocampo, J.A. y J. Ros (2011), "Raul Prebisch y la agenda del desarrollo en los albores del siglo XXI", Seminario "La teoría del desarrollo en los albores del siglo XXI", Santiago de Chile, Comisión Económica para América latina y el Caribe (CEPAL).

OIT (Oficina Internacional del Trabajo) (2005), "Economía informal en las Américas: Situación actual, prioridades de políticas y buenas prácticas", Proyecto Principios y Derechos en el Trabajo en el contexto de la XIII Conferencia Interamericana de Ministros de Trabajo de la OEA, Lima.

Pearson, R. (2004), "Towards the re-politicization of feminist analysis of the global economy", International Feminist Journal of Politics, vol. 6, $\mathrm{N}^{\circ} 4$, Taylor \& Francis.

Piore, M.J. y C.F. Sabel (1984), The Second Industrial Divide, Nueva York, Basic Books.

Rani Uma y Jeemol Unni (2009), "Do economic reforms influence home-based work? Evidence from India”, Feminist Economics, vol. 15, $\mathrm{N}^{\circ} 3$, Taylor \& Francis.

Rendón, G.T. y C. Salas (2000), Segregación y diferencias salariales por género. Hipótesis y evaluación empírica, México, D.F., Secretaria del Trabajo y Previsión Social.

Thompson, E.P. (1963), The Making of the English Working Class, Londres, V. Gollancz.

Tokman, V.E. (2008), "Flexiguridad con informalidad: opciones y restricciones", serie Macroeconomía del Desarrollo, $\mathrm{N}^{\circ} 70$ (LC/L.2973-P), Santiago de Chile, Comisión Económica para América Latina y el Caribe (CEPAL). Publicación de las Naciones Unidas, $\mathrm{N}^{\circ}$ de venta: S.08.II.G.83.

White, H. (1982), "Maximum likelihood estimation of misspecified models", Econometrica, vol. 50, $\mathrm{N}^{\circ} 1$, Nueva York, The Econometric Society. 